Portland State University

PDXScholar

$1-1-2011$

\title{
The Expressive Goals of Bias Crime Legislation and the Media
}

Louis Panush

Portland State University

Follow this and additional works at: https://pdxscholar.library.pdx.edu/open_access_etds Let us know how access to this document benefits you.

\section{Recommended Citation}

Panush, Louis, "The Expressive Goals of Bias Crime Legislation and the Media" (2011). Dissertations and Theses. Paper 206.

https://doi.org/10.15760/etd.206

This Thesis is brought to you for free and open access. It has been accepted for inclusion in Dissertations and Theses by an authorized administrator of PDXScholar. Please contact us if we can make this document more accessible: pdxscholar@pdx.edu. 
The Expressive Goals of Bias Crime Legislation

and the Media

by
Louis Panush

A thesis submitted in partial fulfillment of the requirements for the degree of

Master of Science

in

Political Science

Thesis Committee:

Christopher Shortell, Chair

Melody Ellis Valdini

Birol Yesilada

Portland State University

(C)2011 


\begin{abstract}
State level bias crime legislation was passed throughout much of the United States over the last three decades. Beyond their prosecutorial or instrumental application, bias or hate crime laws serve an expressive or messaging function. This function is meant to promote societal cohesion through the rejection of hateful ideologies, as well as signal to attacked or marginalized members of communities that the government is directly addressing the effects of bias crime. As the number of reported hate crimes in the United States remains essentially level, it is of importance to assess how well the expressive function is performing. Following a background on the development, debate, and variation of bias or hate crime law, this project focuses on a content analysis of prominent state level media with the expectation that the expressive success of laws can be detected in bias crime coverage. It is found that bias crime related stories were featured with greater regularity in the states of Washington and Minnesota, which have passed extensive bias crime legislation. Bias crime related stories were far less prominent in South Carolina, which has no bias crime laws. The State of Wyoming, another state with no bias crime laws, displayed a surprisingly large amount of coverage, primarily as the result of the high-profile murder of Matthew Shepard in 1998.
\end{abstract}


Table of Contents

\author{
Abstract- i \\ List of Tables- iii \\ List of Figures- iv \\ Chapter 1 \\ Introduction-1 \\ Chapter 2 \\ The Development and Debate of Bias Crime Legislation- 7 \\ Chapter 3 \\ Bias Crime Laws and Their Variations at the State Level- 39 \\ Chapter 4 \\ Profiles of Content Analysis States- 50 \\ Chapter 5 \\ Methodology of Content Analysis- 60 \\ Chapter 6 \\ Results of Content Analysis- 67 \\ Chapter 7 \\ Discussion and Conclusion- 87 \\ References- 94
}




\section{List of Tables}

Table 1-

Local and National Articles in The Seattle Times: 1992-2010- Pg. 70

Table 2-

Local and National Articles in Minneapolis Star-Tribune: 1989-2010- Pg. 74

Table 3-

Local and National Articles in The Charleston Post and Courier: 1995-2010- Pg. 77

Table 4-

Local and National Articles in The Wyoming Tribune-Eagle: 1997-2010- Pg. 83

Table 5-

Local and National Articles in Casper Star-Tribune: 2003-2010- Pg. 85 


\section{List of Figures}

Figure 1-

FBI Reported Hate Crimes in the United States: 1996-2009- Pg. 65

Figure 2-

Bias Crime Related Articles in The Seattle Times: 1992-2010- Pg. 69

Figure 3-

FBI Reported Hate Crimes in the State of Washington: 1996-2009- Pg. 72

Figure 4-

Bias Crime Related Articles in Minneapolis Star-Tribune: 1989-2010- Pg. 73

Figure 5-

FBI Reported Hate Crimes in the State of Minnesota: 1996-2009- Pg. 75

Figure 6-

Bias Crime Related Articles in The Charleston Post and Courier: 1995-2010- Pg. 78

Figure 7-

FBI Reported Hate Crimes in the State of South Carolina: 1996-2009- Pg. 80

Figure 8-

Bias Crime Related Articles in The Wyoming Tribune-Eagle: 1997-2010- Pg. 82

Figure 9-

Bias Crime Related Articles in Casper Star-Tribune: 2003-2010- Pg. 84

Figure 10-

FBI Reported Hate Crimes in the State of Wyoming: 1996-2009- Pg. 86 


\section{Chapter 1:}

\section{Introduction}

State level bias or hate crime legislation has enjoyed widespread passage over the last twenty-five years throughout the United States. It has been put in place to address and most often increase penalties for crimes that are "motivated, in whole or in part, by the offender's bias against a race, religion, sexual orientation, ethnicity/national origin, or disability and are committed against persons, property, or society." ${ }^{1}$ The proliferation of bias crime laws in recent years has been in large part tied to increased public awareness of hate crimes and subsequently concern over such offenses. ${ }^{2}$ A dominant socio-political perspective on such acts emerged in the United States in the latter twentieth century based on the notion that crimes rooted in discrimination present a unique threat to our society. Consistently increasing amounts of advocates and politicians came to agree that hate or bias crime must be isolated and openly addressed in order to secure the kind of inclusive society that a majority of citizens deem ideal. Therefore, rather than simply wishing to effectively prosecute and perhaps eliminate crimes motivated by prejudicial ideologies, bias crime laws provide an example of a government's wish to support diversity and foster a sense of societal cohesion. Most advocates of increasing punishment for bias-motivated crimes view the ability to "send a message to the larger community"3 as being a primary objective behind hate crime laws.

\footnotetext{
${ }^{1}$ Definition as outlined by Federal Bureau of Investigation crime statistics found at: http://www2.fbi.gov/ucr/hc2009/methodology.html. Accessed on March 25, 2011.

${ }^{2}$ Levin, J. \& McDevitt, J. (2002). Hate Crimes Revisited: America's War on Those Who Are Different. Westview Press: Boulder, Colorado.

${ }^{3}$ Phillips, N. D. (2009). The prosecution of hate crimes: the limitations of the hate crime typology. Journal of Interpersonal Violence 24, 5: 883-905.
} 
Addressing effects that might possibly extend beyond the actual biased crime itself are by no means the only objective of hate crime laws. Hate crime laws "serve both expressive and instrumental functions." 4 Indeed, "societal harm," 5 in the form of community unrest or retaliatory crimes was a focus of the argument made by the state of Wisconsin in Wisconsin v. Mitchell, the Supreme Court case that has essentially provided the framework for subsequent construction of bias crime laws and legislation. In a unanimous opinion Chief Justice Rehnquist wrote that "the state's desire to redress" these "perceived harms provides an adequate explanation for the penalty-enhancement provision." ${ }^{6}$ However, concrete assessments of how well bias crime laws prevent the most direct instrumental harms of hate crimes can be difficult to achieve. The national totals of reported hate crimes over the last fifteen years have remained essentially level. There has been variation within individual states, but often this can be owed to changes in categorization or reporting procedures. ${ }^{7}$ States have also often had trouble applying hate crime laws to arrests and prosecutions, and theoretically an amount much smaller than the actual number of bias crimes that occur are reported each year. ${ }^{8}$ Additionally, there is a lack of uniformity of laws across states and inconsistencies in the way hate crimes are reported. ${ }^{9}$ All of this adds up to the creation of very murky picture of 'instrumental'

\footnotetext{
${ }^{4}$ Bleich, E. (2007). Hate crime policy in Western Europe: responding to racist violence in Britain, Germany, and France. American Behavioral Scientist 51, 2: 149-165.

${ }^{5}$ Wisconsin v. Mitchell, 508 U. S. 476, 488 (1993).

${ }^{6}$ Ibid.

${ }^{7}$ Statistics compiled at http://www.adl.org/combating_hate/HCSA_10year.asp. Accessed on March 25, 2011.

${ }^{8}$ Dixon, L. \& Ray, L. (2007). Current issues and developments in race hate crime. Probation Journal 54, 2 : $109-124$.

${ }^{9}$ Phillips (2009).
} 
success. Just looking at the instrumental outcomes can leave one asking what, if any, effect bias crime legislation is having.

However, if we look at the more abstract and expressive goals so often mentioned in the advocacy of bias or hate crime legislation, perhaps a more satisfying assessment of effectiveness can be ascertained. Central to measuring the messaging effects of hate crime laws is the public's perception of the hate crimes, bias crime legislation itself, and the issues, both socio-political and philosophical, that surround this area of law.

Some direct public opinion data exist regarding how hate crime legislation is viewed. Still, polls attempting to glean a sense of how the public feels about hate crime and its prosecution are few and far between. This is particularly true at the state level, where one must look to more acutely analyze what difference hate crime legislation has since there is a great deal of variance between state laws. It is notable that when polling has been conducted in recent years a generally favorable view of hate crime legislation is expressed. For example, a May 2007 Gallup poll taken around the time that a Democratic Congress was first attempting to pass federal hate crime legislation that would include gender, sexual orientation, and gender identity as protected categories showed evidence of widespread public support for such a measure. The inclusion of the new protected categories was even supported by well over fifty percent of Republicans and selfidentified conservatives, ${ }^{10}$ which are the kinds of groups that have traditionally been

\footnotetext{
${ }^{10}$ Found at: http://www.gallup.com/poll/27613/Public-Favors-Expansion-Hate-Crime-Law-Include-SexualOrientation.aspx. Accessed on March 23, 2011.
} 
those most opposed to the existence of bias crime laws and their further expansion once in $^{\text {place. }}{ }^{11}$

These results show that despite a consistently vocal opposition, the popularity of bias crime legislation is considerable and has possibly grown amongst the overall United States population in recent years. However, a poll like this does not indicate whether or not the relative popularity of hate crime laws has increased as a result of legislation being enacted. It does not tell us if the expressive message being sent through bias crime legislation is being significantly received.

Less direct than public opinion, but perhaps a more readily available method of assessing public perception and the dissemination of the expressive goals of bias crime law at the state level, is the visibility and portrayal of these laws in the media. Therefore, it is of value to explore whether or not the passage of hate crime laws or bias crime legislation has an effect on how hate crime is handled by the media. Do states with a greater amount of hate crime laws and their populations place greater emphasis on the acknowledgment or awareness of hate crime after the passage of such laws, and is this reflected in the media? A major goal set forth by the proponents of bias crime legislation is the abstract notion of maintaining or increasing societal cohesion, but measuring something like societal cohesion is a difficult task and it is hard to imagine that it can be done clearly or conclusively. Seemingly, though, communities that expose, label, and address the issues that surround hate crimes in open public forums such as the media are making more direct attempts to eradicate the underlying ideologies that lead to such acts.

\footnotetext{
${ }^{11}$ Soule, S. A. \& Earl, J. (2001). The enactment of state-level hate crime law in the United States: intrastate and interstate factors. Sociological Perspectives 44, 3: 281-305.
} 
Whether or not these dynamics are creating a more cohesive society is difficult to measure, but they reflect that the purported expressive goals of bias crime legislation are possibly taking hold.

Thus, this piece will attempt to garner some sense of how bias or hate crime legislation might be moving expressive goals forward through a content analysis of local media. The first chapter will look at the emergence of hate crime as a widely used term and category relating to bias motivated criminal acts before moving on to analyzing issues relating to bias crime laws in the political, constitutional, and philosophical spheres. It will examine the arguments utilized by those who have and continue to argue for the enactment of laws aimed at hate crimes. A review of the Supreme Court case history regarding bias crime legislation will then be conducted in order to outline the constitutional debate surrounding these laws and ultimately their validation at the hands of the Court. I will touch on the political opposition to hate crime laws and the philosophical debate in the literature will be briefly covered. All of this will provide a background for my original research on media coverage of hate crimes and bias crime legislation. It is material essential to comprehending how hate crime laws have emerged in the United States. Also, it is important in understanding why, when attached to an existing crime, a restriction or penalization of certain kinds of speech has been largely justified within this strongly liberal society or, in the case of some communities, why it has not.

The second chapter will cover in greater detail the kind of laws that have been passed at both the federal and state levels. It will look at the variance between the types 
of laws according to the distinction between these two levels, but more importantly it will describe the differences in how states have approached bias crime legislation. The second chapter will end by profiling the four states featured in this project's research; Washington, Minnesota, South Carolina, and Wyoming.

Finally, the third chapter will involve a content analysis of how the media in these four states above cover bias or hate crime and the issues that surround it. Initially, this will be helpful in simply determining whether or not measurements of the expressive effect of bias crime legislation can be found through looking at the media. If it does in fact yield data useful in this sense, then this piece will attempt to identify what kind of effect the expressive or messaging aspects of bias crime legislation have or have not had on the public in these four states. 


\section{Chapter 2:}

\section{The Development and Debate of Bias Crime Legislation}

The aforementioned relationship between public awareness and concern regarding hate crime and an increase in bias crime legislation is made apparent when one considers that bias crimes have arguably been present throughout the history of the United States. Yet, only in the last three decades have laws directly addressing such crimes been created. Aggression directed towards individuals or groups based on their race, ethnicity, religious affiliation, sexuality, or any of the many other descriptive categories that exist in U.S. society is not a new phenomenon. The growing popularity of the term hate crime in recent decades was not a result of such crimes suddenly appearing. For instance, as far back as World War I the Federal Bureau of Investigation began focusing on the kind of crimes that what would come to be termed hate crime in response to the activities of the Ku Klux Klan. ${ }^{12}$ Of course, hate crimes did not suddenly appear around this time either. It can be argued that the entire history of the United States is filled with crimes that could be categorized as being based on bias or hate if contemporary standards were applied. This is particularly so in the case of relations between different racial or ethnic groups. When looking at the dynamics of slavery, the marginalization of an indigenous population, and large influxes of immigrant populations, one does not need to strain to uncover a history that was arguably populated with a much larger amount of crimes based on bias then we currently see. ${ }^{13}$ In fact, there is logic in speculating that there has been a reduction in bias crime since darker periods in U.S. race relations, and that this is perhaps

\footnotetext{
${ }^{12}$ Hate crime background accessed on March 25, 2011, found at: http://www.fbi.gov/aboutus/investigate/civilrights/ hate_crimes/hate_crimes.

${ }^{13}$ Levin, J. \& McDevitt, J. (2002).
} 
related to a current focus throughout the United States on isolating and prosecuting these crimes.

While the spread of the term hate or bias crime both politically and legally can superficially give the sign that such crimes have increased considerably in the last few decades, the opposite is perhaps the case. Essentially, political strides made by minority rights movements in the latter half of the twentieth century helped foster a more positive view of a pluralist society. Previously, rights movements were simply aimed at creating something that would even remotely resemble an equitable society for those beyond the white, male, straight and wealthy. Compared to objectives such as voting rights, or equal access to educational or employment opportunities, bias crime legislation represents a much more detailed and finely tailored approach to promoting equality and societal cohesion; an approach that is now more accessible due to the larger strides made in previous years.

Still, while hate or bias crimes were by no means a new development in the years leading up to the passage of state level legislation, this is not to suggest that bias crime laws were merely the natural outgrowth of a progressing society. There were clear factors that acted as an impetus and influenced a perceived socio-political need to create hate crime laws. High profile crimes in the 1980s and 90s that victimized individuals and groups based on their descriptive characteristics prompted public officials in many U.S. states and at the federal level to take notice of what were now being called 'hate' crimes. ${ }^{14}$ Additionally, many white separatist groups, such as neo-Nazi skinheads became more vocal, prominent, and their extremist presence entered the American

${ }^{14}$ Ibid. 
consciousness, ${ }^{15}$ even as such groups' philosophies came nowhere near being relevant to mainstream debate. The kind of crime now being referred to with the prefix of 'hate' had not necessarily increased during this period, and the growing awareness of such hate groups did not necessarily imply a higher population of bigoted citizens. However, the continued existence of crimes and groups so "prevalent and vicious... especially after the elimination of Jim Crow, the massive civil rights struggle of the 1960s and the effective activism of the women's movement" ${ }^{16}$ perhaps magnified their impact and created a greater sense of crisis. However, statistically speaking, crimes falling under the category of hate or bias have never accounted for anywhere near even one percent of total crime in any state since the FBI started compiling hate crime statistics in the early $1990 \mathrm{~s}^{17}$

The statistical reality of hate crime and the amount of total crime it accounts for serves to highlight that a major component, if not the major drive, of bias crime legislation is based on the notion that the main effects of hate crimes are largely abstract. Advocates of increasing punishment for bias-motivated crimes view the ability to "send a message to the larger community" 18 as being perhaps the main objective behind hate crime laws. In fact, some feel that even on the most directly instrumental levels that "the deterrent may potentially lie in the declaratory value of legislation rather than the enhanced penalty," 19 and the "expressive message of the laws, rather than their manipulation of behavioral incentives... is most effective in reducing the threat that bias

\footnotetext{
${ }^{15}$ Hate crime background accessed on March 25, 2011, found at: http://www.fbi.gov/about-us/investigate/ civilrights/hate_crimes/hate_crimes.

${ }^{16}$ Levin, J. and McDevitt, J. (2002).

${ }^{17}$ Uniform Crime Reports accessed on March 25, 2011, found at: http://www.fbi.gov/about-us/cjis/ucr/ucr.

${ }^{18}$ Phillips, N. D. (2009). The prosecution of hate crimes: the limitations of the hate crime typology. Journal of Interpersonal Violence 24, 5: 883-905. Pg. 901.

${ }^{19}$ Iganski, P. (1999). Why make 'hate' a crime? Critical Social Policy 19, 3: 386-395. Pg. 388.
} 
crimes hold. ${ }^{20}$ These laws are not simply a means to reduce crime, but even in regard to that objective the overriding message of bias crime legislation is seen as essential.

The broader expressive nature of bias crime legislation is made further understandable when taking into account the claim that hate crimes have effects that theoretically extend beyond the initial victim. On their face, bias crime laws may appear as a disproportionate response when compared to the space they occupy in overall numbers. The proponents of bias crime legislation respond by pointing to the disproportionate impact of hate crimes. Hate crimes are undeniably small in number compared to the amount of similar crimes that have no ideological motivation, but "hate crimes are distinct from the same underlying crime because of the greater harms they inflict." ${ }^{21}$ They are acts that resonate well beyond the superficial boundaries of a singular act, and can lead to the marginalization of groups within a community. This is due to the perceived goals of those perpetrating hate or bias crime, in that their actions reflect "beliefs in their own groups' superiority and the inferiority of the victims and the groups to which they belong." 22 Bias crimes are seen as "message crimes intended to intimidate the victim and the members of his or her shared community., ${ }^{, 23}$ As a result, advocates feel the state has a compelling interest in punishment that exceeds the superficiality of the act, and a pointed counter-message should be sent at the prosecutorial level which will disseminate to the community as a whole.

\footnotetext{
${ }^{20}$ Altman, A. (2001). The democratic legitimacy of bias crime law: public reason and the political process. Law and Philosophy 20, 2: 141-173. Pg. 170-171.

${ }^{21}$ Iganski, P. (2001). Hate crimes hurt more. American Behavioral Scientist 45, 4: 626-638. Pg. 633.

${ }^{22}$ Saucier, D. A., Hockett, J. M., Zanotti, D. C., \& Heffel, S. (2010). Effects of racism on perceptions and punishment of intra- and interracial crimes. Journal of Interpersonal Violence 25, 10: 1767-1784. Pg. 1768. ${ }^{23}$ Lim, H. A. (2009). Beyond the Immediate Victim: Understanding Hate Crimes as Message Crime. Hate Crimes Vol. 2: The Consequences of Hate Crime. Eds. Perry, B. \& Iganski, P. Praeger Publishers: Westport, CT.
} 
For instance, a rash of petty vandalism in a community that is seemingly random and destructive for its own sake, which happens to affect multiple Jewish owned businesses, would no doubt be a nuisance and would most likely make business owners fear for their property. However, if in that same community a synagogue was vandalized and defaced with the use of racially derogatory terms or symbols such as the swastika, even if only once, it would constitute a form of vandalism that effects a community more than multiple ideologically neutral acts of property destruction. Rather than affecting only those who directly have an interest in the property that is targeted, vandalism driven by bias serves to make every Jewish member of a community feel unwanted or threatened by the perpetrators of the crime. It is theoretically a crime with broader intentions and a broader impact. Subsequently, then, the approach to constructing laws that address bias crime would be based on the notion that 'message crimes,' as hate or bias crimes are so often labeled or framed, ${ }^{24}$ require a response that is comparably impactful. Bias crime legislation as it relates to addressing the above scenario should serve to be an expression and the promotion of what is presumably the community majority's wish for a sense of equality, cohesion, and the embracing of diversity. The Anti-Semitic viewpoints attached to the crime are shamed as a means of deterrence and a message sent to the Jewish members of a community that they receive the support of the population on the whole through this government action.

\footnotetext{
${ }^{24}$ Iganski, P. (2001). Virginia v. Black, 538 U. S. 343, (2003) In reference to cross burning in the opinion of the court written by Justice O'Connor, as well Justice Souter's opinion of concurrence in part and dissention in part. Lim, H. A. (2009). Liberman, Michael “Hate Crime Laws: Punishment to Fit the Crime.” Dissent Magazine July, 82010.
} 
Also greatly aided by the messaging of bias crime law, central to the notion of promoting societal cohesion, and mentioned in Chief Justice Rehnquist's opinion in Wisconsin v. Mitchell, is the theoretical usefulness of bias crime law as a means to stop retaliatory action. Essentially, if a crime that is perceived as an attack on an entire group is effectively and openly prosecuted as such, it will help discourage members of the initially attacked group from engaging in similar acts, thus avoiding escalation and a possible larger community conflict. Such a dynamic between different racial, ethnic, and religious groups is seen as enough of a threat that 'retaliatory' hate crimes are often categorized separately by those researching bias motivated crime. Advocates for bias crime legislation contend that hate crime laws and their usage projects the image that the state and the community on the whole do not tolerate bias motivated crimes, and vigilante responses are therefore not the only avenue to justice. ${ }^{25}$

Indeed, the claims of the uniquely wide reaching and expressive nature of bias crimes often find their way into the wording of state level legislation, along with specific reference to the interest of the government in messaging through addressing hate crime. The State of Washington, which has enacted some of the most extensive bias crime legislation in the country, provides a great example of the focus on message. A Washington penalty enhancement law passed in 1993 addressing malicious harassment that is biased in nature opens by expressing concern that was increasingly prevalent in many states around that time. Basically, "that crimes and threats against persons because of their race, color, religion, ancestry, national origin, gender, sexual orientation, or

\footnotetext{
${ }^{25}$ Levin and McDevitt (2002), Phillips (2009)
} 
mental, physical, or sensory handicaps are serious and increasing." ${ }^{26}$ It then goes on to make the disproportionate harm claim by stating that "the state interest in preventing crimes and threats motivated by bigotry and bias goes beyond the state interest in preventing other felonies or misdemeanors... or other crimes that are not motivated by hatred, bigotry, and bias, and that prosecution of those other crimes inadequately protects citizens from crimes and threats motivated by bigotry and bias." ${ }^{27}$ This bias crime law further addresses the history of both cross-burning and swastikas, and the message sent by the use of these symbols in an attempt to "create a reasonable fear of harm in the mind of... a particular person, the person's family or household members, or a particular group"(emphasis added). It is certainly reasonable to interpret the wording of this bill, and subsequently the Washington State Legislatures passage of the bill, just as much an expressive act as it could be deemed an instrumental one.

Not every state has created a record quite as explicit in regard to making clear the reasoning and intention behind enacting bias crime legislation. For example, a search of the legislative record in Minnesota, a state that also has extensive hate crime laws, produces simply a straightforward cataloging of laws and their guidelines with no reference to the findings that led to their construction and passage. Still, it is very likely the Washington State Legislature is not alone in their reasoning and motivation, which perfectly illustrates the expressive and counter-messaging objectives of bias crime legislation. The bill opens with reference to the instrumental need to address a form of crime perceived as an increasing threat, but the majority of the record addresses the more

\footnotetext{
${ }^{26}$ Washington State Law RCW 9A.36.078. Accessed on March 25, 2011, found at: http://apps.leg.wa.gov/RCW.

${ }^{27}$ Ibid.
} 
abstract and perhaps more theoretical harms of bias crime. All the while the Washington law conveys a tone that makes clear an interest in combating ideologies that serve to attack a community standard of inclusiveness and societal cohesion. Later, the research of this project will look specifically at the state of Washington in an attempt to garner a sense of what effect laws like the one related to malicious harassment might have had by analyzing local media.

Of course, a state's interest in expressing distaste for hatefully motivated actions also must consider the reactions of an individual victim to bias crime. Beyond the effects that might possibly be felt by the larger community, arguments for bias crime law frequently cite that hate or bias crimes can also have greater impact on individuals as well as communities. Due to this ability to "inflict distinct emotional harms on their victims",28 hate crimes have a further exceptional quality. It has been frequently argued that the psychological consequences for hate crime victims are more severe than those of nonbias crime victims. ${ }^{29} \mathrm{~A}$ greater psychological harm is often owed to the relative random nature of hate crimes. Victims are selected due to their descriptive qualities. Thus, individuals find it more difficult to rationalize why they were attacked, and have relatively little recourse in regard to avoiding a situation or behavior in the future that might help them eliminate the possibility of being attacked again. Something inherent in the being of those attacked is what leads to their victimization, so victims feel a greater threat exists in the future. ${ }^{30}$ Furthermore, hate crimes are more often reported as physical

\footnotetext{
${ }^{28}$ Wisconsin v. Mitchell, 508 U. S. 476, 488 (1993).

${ }^{29}$ Levin and McDevitt (2002), Saucier, et. al (2010)

${ }^{30}$ Levin and McDevitt (2002), Lim (2009). Iganski, P. (2001) Hate crimes hurt more. American Behavioral Scientist 45, 2: 626-638.
} 
attacks, as opposed to the more indirectly harming acts such as "property damage, vandalism, or arson.",31

Notably, some argue that the instituting of hate crime legislation has the potential to affect society in a manner opposite to what advocates purport. For example, Jacobs and Potter write of the possibility that societal cohesion or racial tension can be exacerbated by high profile hate crime prosecution, and the exclusion of certain groups in legislation. ${ }^{32}$ This raises the possibility that in an attempt to embolden historically attacked groups through bias crime law, the civil rights of other citizens are perceived as being threatened. Furthermore, even some of those who support bias crime legislation feel that these sociological outcomes are largely speculative. For example, in regard to the psychological effect of hate crime, Iganski and Lagou admit that "much of the evidence for the supposed greater harm caused by hate crime has been equivocal."33

Most often, when the arguments for hate crime laws are challenged it is primarily due to possible conflicts with speech rights and the First Amendment. Bias crime legislation is viewed as unconstitutional, and it amounts to what is essentially punishment for character traits or 'thought crimes,' and a slippery slope of threats to basic rights that outweighs any good it can be shown to create. In response, advocates of bias crime laws see such measures as addressing a rare situation that, like others throughout the course of United States jurisprudential history, ${ }^{34}$ appropriately finds justification for the limitation

\footnotetext{
${ }^{31}$ Saucier, et. al. (2010). Pg. 1768.

${ }^{32}$ Jacobs, J. B. \& Potter, K. (1998). Hate Crimes: Criminal Law and Identity Politics. New York: Oxford University Press.

${ }^{33}$ Iganski, P. \& Lagou, S. (2009). How hate crimes hurt more: evidence from the British crime survey. Hate Crimes Vol. 2: The Consequences of Hate Crimes. Eds. Perry, B. \& Iganski, P. Praeger Publishers: Westport, CT.

${ }^{34}$ See Chaplinsky v. New Hampshire, Miller v. California, Ferber v. New York.
} 
or suspension of First Amendment rights. The effects of bias motivated crimes are exceptional and require the kind of exceptional legislation that has been constructed by proponents and the majority of U. S. states. Furthermore, as the Supreme Court made clear in 1992, a law that seeks to criminalize merely hateful speech is not constitutional. ${ }^{35}$ Hate for an individual or group based descriptive characteristics can only be an addition or enhancement to the punishment of an already existing crime. ${ }^{36}$ This is justified because it is seen as essential to the vital interest of maintaining a peaceful and equitable society, and any limiting of speech in this context falls in line with that of prior jurisprudence. However, some don't find the circumstance of bias crime to provide a reasonable exception to the First Amendment Rule and see it as a violation of free speech rights, regardless of its criminal association or sociological and political need.

The relative youth of hate crime law means that the Supreme Court doesn't have an especially long history when it comes to addressing the constitutionality of hate or bias crime legislation. However, it has been addressed multiple times by the Court and has resulted in a great deal of, if not complete, clarity in how such legislation can be constructed. For the most part the outcomes of Supreme Court cases in this area have favored those who support hate crime laws, even if the decisions by the court have required adjustments in the construction of such laws. Due to the momentum enjoyed by bias crime legislation advocates in constitutional jurisprudence, and the Supreme Court providing the technical legal framework for hate crime legislation, it is of value to review

\footnotetext{
${ }^{35}$ R. A. V. v. City of St. Paul Minnesota, 505 U. S. 377 (1992)

${ }^{36}$ Wisconsin v. Mitchell, 508 U. S. 476 (1993).
} 
the cases heard by the Supreme Court before moving on to the political and constitutional objections of its critics.

\section{Bias Crime Law and the Supreme Court}

The distinction between acceptable and unacceptable construction of bias crime laws was primarily outlined by the Supreme Court in the early 1990s in R. A. V. v. City of St. Paul, Minnesota and Wisconsin v. Mitchell, both of which focused on statutes involving hateful or biased actions, but resulted in decidedly different outcomes. These decisions would aid in creating a framework for the influx of legislation at the state level in the following years, particularly the Court's decision in Mitchell. Statutes relating to the punishment of hate or bias motivated action, and laws hostile towards certain speech content would not be entirely struck down in light of the First Amendment. Rather, their constitutionality would hinge upon exactly where and how the element of speech was attached to said actions. Put simply, it was deemed unconstitutional in $R$. A. V. to essentially create a crime based on an action of hateful or biased speech which, excluding the speech, would otherwise not constitute a crime. In Wisconsin v. Mitchell, the Supreme Court ruled that existing crimes, such as the physical assault at issue in the case, could fall subject to a greater penalty if motivated by bias or hate. A hateful or biased motivation could be used in a supplemental capacity when determining how to punish an existing crime. It was not punished in and of itself, as was the case in $R$. A. V. Also, the distinction drawn between the assault in Mitchell and other assault was based on the Court accepting the argument that the expressive nature of bias motivated crime made 
such acts carry a greater weight than similar but ideologically neutral crimes. As a result, the state has a compelling interest and is constitutionally justified in punishing bias crime.

Prior to R. A. V. the Supreme Court had struck down government statutes related to the limiting of hateful or racist speech despite such cases not directly addressing whether it was constitutional to institute hate speech or hate crime laws. In Brandenburg v. Ohio a leader of the Ku Klux Klan was arrested under an Ohio law aimed at criminal syndicalism for remarks he made directed toward racial minorities and the U.S. government. In a unanimous per curium opinion, the Court struck down the Ohio law and the subsequent arrest of Brandenburg. The opinion stated that the statute "as applied purports to punish mere advocacy and to forbid, on pain of criminal punishment assembly with others merely to advocate the described type of action." As a result, the law fell "within the condemnation of the First and Fourteenth Amendments." 37 Different government actions aimed at the suppression of hate speech were taken up by the Court in Socialist Party v. Skokie when the city of Skokie, Illinois passed a series of ordinances as a means to block a planned march by a Neo-Nazi organization in a largely Jewish community. In another per curium opinion, a majority of the Court sided against government attempts to block speech, this time claiming that Skokie was essentially blocking speech before it actually even had the opportunity to occur. ${ }^{38}$

Neither of the preceding cases directly addressed a law that sought to criminalize hate speech. Still, both decisions give a fairly clear indication of where the Court would land regarding such statutes. If speech is not tied to any 'imminent danger' it cannot be

\footnotetext{
${ }^{37}$ Brandenburg v. Ohio, 395 U. S. 444, 449 (1969).

${ }^{38}$ Socialist Party v. Skokie, 434 U. S. 1327 (1977).
} 
curtailed merely based on its abstract advocacy of illegal action. Certainly, a message of intimidation or threat was meant to be sent to a certain group or groups in a community. This is particularly true in Skokie, where there was a blatantly pointed choice of venue for a Neo-Nazi march. However, the state could not usurp basic legal and constitutional rights in an attempt to quell disfavored speech. Theoretically, Chaplinsky v. New Hampshire had provided the basis for curtailing the speech of Brandenburg or the NeoNazis if they were expressing themselves in a venue where it could be deemed 'fighting words,' but in both Brandenburg and Skokie the state was attempting to silence them before they ever got near that point.

While the Court handed down a unanimous decision in $R$. A. V. it is notable that it was split regarding the exact nature of what was problematic with the St. Paul ordinance which forbade "placing on private property a symbol, object, appellation, characterization, or graffiti... which one knows or has reasonable grounds to know arouses anger, alarm or resentment in other on basis of race, color, creed, religion, or gender." ${ }^{39}$ St. Paul based a part of its defense of the ordinance on the notion that the actions it addressed amounted to "fighting words" as outlined by Chaplinsky. A five justice majority of the Court agreed that the actions described by the ordinance could fall under the concept of "fighting words," but the law only covered certain kinds of "fighting words'. The majority found that "those who wish to use 'fighting words' in connection with other ideas... are not covered" and "the first Amendment does not permit St. Paul to impose special prohibitions on those speakers who express views on disfavored

${ }^{39}$ R. A. V. v. City of St. Paul Minnesota, 505 U. S. 377, 380 (1992). 
subjects. ${ }^{40}$ Further, even though the category of 'fighting words' falls outside of First Amendment protection, Justice Scalia wrote that this category is not "invisible" to the Constitution. Because it is not "invisible," the constitution still protects against contentbased discrimination, even when that category might otherwise be regulated. ${ }^{41}$ In acknowledging that a focused limitation of particular kinds of speech might encounter content discrimination problems, St. Paul attempted to justify the ordinance by arguing that it served "compelling state interests." The majority of the Court countered with the view that "an ordinance not limited to the favored topics... would have precisely the same beneficial effect," and that "the only interest distinctively served by the content limitation is that of displaying the city council's special hostility towards the particular biases thus singled out." ${ }^{42}$

A four justice minority concurred regarding the reversal of the Minnesota State Supreme Court's decision to uphold the ordinance, but their reasoning was different than that of the majority. The concurring opinion written by Justice White takes issue with the majority's insistence that an "all or nothing approach" is the only valid manner in which to restrict 'fighting words.' Justice White accuses the majority opinion of "characterizing fighting words as a form of debate," and as a result, lending validity to "hate speech as a form of public debate. ${ }^{43}$ The minority instead rested their objection to the St. Paul ordinance on overbreadth grounds. Essentially, these justices had no problem with the singling out of certain forms of speech under the ordinance, but found it

\footnotetext{
${ }^{40}$ R. A. V. v. City of St. Paul, Minnesota, 505 U. S. 377, 391(1992).

${ }^{41}$ Leeper, R. (2000). Keegstra and R. A. V.: a comparative of the Canadian and U.S. approaches to hate speech legislation. Communication Law and Policy 5, 3: 296-321.

${ }^{42}$ R. A. V. v. City of St. Paul, Minnesota, 505 U. S. 377, 396 (1992).

${ }^{43}$ Ibid. 401, 402.
} 
"unconstitutionally vague." ${ }^{44}$ By rejecting the 'all or nothing approach' to 'fighting words' restriction, Justice White seems to be more sympathetic to the notion that the state has a reasonable interest in determining in some manner which kinds of ideologies it deems damaging to societal cohesion and community inclusion. Thus, he adopts a position more in line with those who have strongly advocated for the institution of bias crime provisions and the expressive objectives they embody.

The split in reasoning of the Court's decision in R. A. V. does not provide an example of a debate nearly as broad as that found in the strictly political world, or in the literature examining hate speech and bias crime law. Still, it does represent a slight glimpse into the general divide between those who feel it is constitutionally valid to legally discourage actions tied to what the majority of society deems hateful or divisive, and those who feel that virtually any attempt to single out certain types of speech, even with the best of intentions, creates a slippery slope that is prohibited by the First Amendment. The rejection of pure hate speech laws, along with the acceptance of bias crime legislation like penalty enhancements, shows that the Court has effectively taken a moderate position within this debate.

The Supreme Court later returned to the specific issue of cross burning in Virginia v. Black. In Black, a majority of the Court upheld the banning of cross burning as a form of intimidation, while striking down an element of the statue that would consider any cross burning as prima facie evidence of intimidation. This apparent split from the decision in $R$. A. $V$. was justified by claiming that the previous decision did not state "that the First Amendment prohibits all (italics original) forms of content-based discrimination ${ }^{44}$ Ibid, 411. 
within a proscribable area of speech," 45 and that "the Virginia law does not single out for opprobrium only that speech directed toward 'one of the specified disfavored topics."' Of course, the act of burning a cross as a form of intimidation is commonly known to be associated with a particular perspective or topic, but the all-encompassing nature of the Virginia statute was deemed by a majority of the Court as passing First Amendment muster where the more specific St. Paul ordinance in $R$. A. V. was seen as running afoul.

The majority did appear to find a difference between the Virginia law and the St. Paul ordinance which related directly to objections raised in $R . A . V$. and presented a reason for separate consideration of the two laws in relation to the First Amendment. Still, a three person minority saw the decision in $R$. A. V. as implication that the Virginia law was also unconstitutional. Justice Souter wrote that "although the Virginia statue in issue...contains no...express 'basis of' (race, color, creed, religion, or gender) limitation on prohibited subject matter, the specific prohibition of cross burning with intent to intimidate selects a symbol with particular content from the field of all proscribable expression meant to intimidate." ${ }^{46}$ In essence, Justice Souter still saw the singling out of cross burning as representing the disfavored topic problem raised by the majority in $R$. $A$. $V$.

The majority's justification for holding in favor of a cross burning statue is by no means unreasonable, but it can still perhaps be viewed as a bit of a departure from the spirit of the decision a decade earlier in $R$. A. V. Certainly, that seems to be the opinion of Justice Souter's dissent. By pulling on what could be considered a small thread separating

${ }^{45}$ Virginia v. Black, 538 U. S. 343, 361 (2003)

${ }^{46}$ Ibid, 381 . 
Black from R. A. V. the Court was able to allow the state of Virginia to attempt to eliminate an activity which had historically been employed to invoke the "fear of violence" and "the disruption that fear engenders" $" 47$ within the American black population. Interestingly, this Virginia statute, undoubtedly aimed at signaling to the citizens of that state that the intimidation of black citizens would not be tolerated, survived a constitutional test because it never directly isolated that group or any group, for protection.

As with Black, it is not inaccurate to perceive the decision in Wisconsin $v$. Mitchell as the Court finding a way to look at legislation related to hate speech with less skepticism than it did in $R . A$. V. However, there are important differences between the two cases that led to a unanimous Court, both in the decision and opinion of Mitchell. Perhaps the most important difference was that in R. A. V. and Black the Court was considering laws that essentially created a crime or illegal action, while Mitchell saw the state of Wisconsin attempting to add greater weight to a sentence imposed for an already proven criminal action. On this point, in the opinion authored by Chief Justice Rehnquist, he wrote that "the ordinance struck down in $R$. A. V. was explicitly directed at expression i.e., 'speech' or 'messages,' the statute in this case is aimed at conduct unprotected by the First Amendment." 48 This distinction is, of course, central to the line drawn between hate speech and hate crime laws. It was crucial in creating the framework for statutes passed in numerous states in the following years. The wish of states to message the need for tolerance and to attack divisive ideologies was made clearly constitutional if it was

\footnotetext{
${ }^{47}$ Ibid, 360.

${ }^{48}$ Wisconsin v. Mitchell, 508 U.S. 476, 487 (1993)
} 
attached to already criminal actions. When hateful views are attached to conduct not protected by the First Amendment the government is given an opportunity to support favored viewpoints, because the laws passed have a more directly instrumental function. This is the case even if some of the instrumental functions mentioned by Justice Rehnquist such as "retaliatory crimes" or "community unrest" 49 are still often considered speculative.

Mitchell argued that the Wisconsin penalty enhancement violated the First Amendment because it amounted to punishing someone for their bigoted viewpoint. Chief Justice Rehnquist responded to this argument by writing that "the First Amendment...does not prohibit the evidentiary use of speech to establish the elements of a crime or to prove motive or intent" 50 and "traditionally, sentencing judges have considered a wide variety of factors in addition to evidence bearing on guilt in determining what sentence to impose on a convicted defendant." ${ }^{, 51}$ Mitchell also claimed that sentence enhancements like those found in the Wisconsin Statute fell prey to being overbroad and would create a 'chilling effect' regarding First Amendment and freedom of speech. Rehnquist responded that "the prospect of a citizen suppressing his bigoted beliefs for fear that evidence of such beliefs will be introduced against him at trial...is simply too speculative a hypothesis to support Mitchell's overbreadth claim."

\footnotetext{
${ }^{49}$ Ibid, 488.

${ }^{50}$ Ibid, 489 .

${ }^{51}$ Ibid, 485 .

${ }^{52}$ Ibid, 489.
} 
In 2000, the Supreme Court again heard a case involving bias crime penalty enhancement in Apprendi v. New Jersey ${ }^{53}$ In Apprendi, the Court invalidated a New Jersey hate crime law, but this was due to the process that led to the penalty enhancement being employed. The facts that were utilized in giving Apprendi a harsher sentence were not submitted to a jury, but were rather based entirely on the determination of a judge in the case, which was deemed improper. ${ }^{54}$ Therefore, nothing in the general acceptance of penalty enhancement provisions found in Mitchell was altered and it continued to stand as the definitive perspective of the Court on common hate crime laws.

The unanimous decision in Mitchell and its relative clarity has created a great deal more certainty for states when constructing sentence enhancement statutes than they enjoy when creating other kinds of laws that relate to hate speech, like those at issue in $R$. A. V. and Black. A great deal of hate crime legislation has been passed since the Mitchell decision and it has often been directly tailored to meeting the requirements found in the Wisconsin law and outlined in Chief Justice Rehnquist's opinion. Still, laws outside of the realm of penalty enhancement have not necessarily faced a great deal of opposition considering the less decided nature of the Supreme Court's perspective. Notably, the ruling in $R$. A. $V$. only applied to that case, and although it was perhaps somewhat loosened in Black, it could theoretically still be applied to statutes in certain states that bear a greater similarity to the law in R. A. V. than to Black's Virginia statute. ${ }^{55}$

\footnotetext{
${ }^{53}$ Apprendi v. New Jersey, 530 U. S. 466 (2000).

${ }^{54}$ Epstein, L. \& Walker, T. G. (2009). Constitutional Law for a Changing America: Rights, Liberties and Justice. CQ Press: Washington, D. C. Pg. 550.

${ }^{55}$ Levin, J. \& McDevitt, J. (2002).
} 
To use Washington State again as an example, a subsection in a Washington bias crime statute addresses cross burning by attaching the act specifically to the "property of a victim whom is or who the actor perceives to be of African American heritage." At first this appears to be completely at odds with the requirements laid out by the Court in $R$. A. $V$. and Black. As a possible means to account for this, the law then goes on to say that this subsection "applies to the creation of a reasonable inference for evidentiary purposes" and thus "does not restrict the state's ability to prosecute a person under subsection $(1)^{56} \ldots$ when the facts of a particular case do not fall within ... this subsection. ${ }^{, 57}$ This would appear to generalize the Washington law in a manner similar to the Virginia law in Black. However, the rest of the law does not cover "any persons or groups of persons," 58 but rather subsection (1) represents a laundry list of protected groups in a similar fashion as the St. Paul ordinance in $R$. A. $V$. The Washington State law that addresses cross burning has stood for almost two decades and likely will face little challenge in the future, even if R. A. V. can be applied to existing laws. The decision in Black also makes another dissection of cross burning statues seem unlikely. Still, looking at existing statutes such as the one in Washington serves to illustrate that the willingness to challenge laws related to hate speech and bias crime has perhaps waned since the early nineties. Essentially, the matter may be stalled in regard to challenges in the courts, even if some issues are not totally resolved.

\footnotetext{
${ }^{56}$ This references the broad categories covered by the law which includes race, color, religion, ancestry, national origin, gender, sexual orientation, or mental, physical, or sensory handicap.

${ }^{57}$ Washington State Law RCW 9A.36.080. Accessed on March 25, 2011, found at: http://apps.leg.wa.gov/.

${ }^{58}$ Virginia v. Black, 538 U. S. 343, 348 (2003).
} 
The lack of challenge to laws that relate to hateful speech and bias crime has been prompted, at least in part, by the generally strong public support they have enjoyed, particularly following high profile cases such as the murders of James Byrd and Matthew Sheppard in the late 90s, and a growing public awareness and concern over such motivated crimes or actions in the last thirty years. ${ }^{59}$ However, while the decision of the Supreme Court in Mitchell and the relative popularity of bias crime legislation may have slowed the challenge and reversal of such laws, it certainly has not put a stop to the debate surrounding it in the political, legal, and criminology fields. Both in relation to the effectiveness of the laws, and whether or not these laws unfairly punish the views of criminals, and are thus inherently unconstitutional as a violation of speech rights and the First Amendment.

\section{The Socio-Political Response of Critics}

The rate at which the concept and categorization of hate crimes entered the American consciousness, and subsequently how quickly legislatures around the country moved to pass laws addressing them, is a testament to the overall popularity of such measures. Naturally, though, support has not and does not exist across the board. Objections to bias crime law and penalty enhancements have been a constant. Most states, after a sometimes lengthy political debate, have passed bias crime legislation and in following years increased its reach and detail, but opposition often remains. In a small minority of states like Arkansas Indiana, South Carolina, and Wyoming, opposition to hate crime legislation has dominated, and few, if any, laws targeting crimes of a biased

\footnotetext{
${ }^{59}$ Levin and McDevitt (2002).
} 
nature have been instituted. Any discussion of the justifications used to support bias crime legislation, both in regard to its instrumental and expressive functions, must include the views of those who see it as damaging. The arguments against hate or bias crime laws are varied, and deserve to be taken seriously. This is especially true of many constitutional objections that have and continue to be raised, despite the Supreme Court's approval of bias crime laws, provided they follow the appropriate guidelines put forth in a number of cases over the last twenty years.

As was briefly mentioned previously, some feel that the cohesive societal impact so consistently trumpeted by advocates of bias crime legislation, and even sometimes accepted by those who oppose it on other grounds, ${ }^{60}$ is a myth. ${ }^{61}$ Instead of creating a greater sense of inclusion in a society and making its members progressively less comfortable with ideologies that lead to bias crime, hate crime laws will make many citizens resentful of those protected. A claim along these lines is sometimes backed by referencing the small statistical sum that bias crimes account for in overall numbers. Essentially, the emphasis placed on hate crimes in the last three decades has been blown out of proportion relative to the amount of hate crime that actually exists. ${ }^{62}$ Due to this, rather than quelling tensions between societal groups, the advocates of bias crime legislation run the risk of creating greater divisiveness. Naturally, this argument also relies on either the downplaying or complete rejection of the notion that bias crime has a broader or more substantial impact and that "hate crimes are less severe; victims of

\footnotetext{
${ }^{60}$ Hurd, H. M. (2001). Why liberals should hate "hate crime legislation." Law and Philosophy 20, 2: $215-$ 232.

${ }^{61}$ Jacobs and Potter. (1998).

${ }^{62}$ Kopel, D. (2003) "Hate Crime Laws: Dangerous and Divisive." Paper for the Independence Institute. Golden, Colorado. Found on April 4, 2011 at: http://www.i2i.org/
} 
various crime types suffer approximately the same psychological injury." ${ }^{63}$ This claim has at times been helped along by advocates of bias crime legislation when they make the argument that the 'message' element of the laws are worthwhile even if no lessening of greater harm, a reduction in number of crimes, or the increasing of societal cohesion can be empirically proven. ${ }^{64}$ Basically, in an attempt to reinforce or embolden the value of hate crime laws by referencing their theoretical usefulness as abstract messaging tools, advocates have sometimes made other arguments look a bit disingenuous.

This widely used rhetorical argument against bias or hate crime legislation, that rather than these laws creating a more inclusive or equitable society they actually serve to unequally protect one group or class in the population, is often combined with the accusation that prosecuting bias crimes separately from similar ideologically neutral crimes unfairly punish the thoughts or feelings of an individual. For example, in 2009, future Speaker of the House John Boehner opposed federal hate crime legislation aimed at protecting citizens based on sexual orientation referring to it as "thought crimes legislation" that "places a higher value on some lives than others." ${ }^{65}$ Boehner went on to say that he and other "Republicans believe that all lives are created equal, and should be defended with equal vigilance," ${ }^{, 66}$ implying that a penalty enhancement in response to crime directed at someone based on their sexual orientation would entail weaker prosecution for others. Such rhetorically heated opposition is by no means exclusive to

\footnotetext{
${ }^{63}$ Ibid. Pg. 6

${ }^{64}$ Kahan, D. M. (2001). Two liberal fallacies in the hate crime debate. Law and Philosophy 20, 2: 175-193. Pg. 184.

${ }^{65}$ Montopoli, Brian. "Why GOP Leader Opposes Hate Crimes Protection for Gays.” October 13, 2009. Found on April 4, 2011 at: http://www.cbsnews.com/8301-503544_162-5381671-503544.html.

${ }^{66}$ Ibid.
} 
purely political figures. Academics such as Jacobs and Potter make similar, if somewhat more sophisticated claims by saying that bias crime laws essentially amount to "thought crime" because they "provide extra punishment based on the offender's politically incorrect opinions and viewpoints. ${ }^{.67}$ Rather dramatically, Nearpass even goes as far as to suggest that critics of this bias crime law have been labeled by the "politically correct movement" as "intolerant bigots," which has contributed to the stifling of debate around the subject. ${ }^{68}$

It is of note that at the time of the preceding quotes by Rep. Boehner he did express support of existing federal bias crime protections due to a claim that those groups protected outside of sexual orientation or gender identity possessed immutable characteristics. This position highlights that many who may have generally taken issue with any bias crime legislation in the past have perhaps come to accept its presence in some forms after two decades of debate and momentum in favor of hate crime measures. It also provides an example of the greater amount of contention that still exists surrounding the validity of sexual orientation or gender identity as being protected categories in bias crime legislation. This is due to a somewhat frequent, and often religious, perception that those who fall into this categorization have essentially made a lifestyle choice, and it is not an immutable characteristic like those found in other hate crime protected categories. A more fervent and widespread opposition to gay, lesbian, bisexual, and transgender civil rights amongst American conservatives has also made conservative politicians fearful of measures covering these groups. Invoking a 'chilling

\footnotetext{
${ }^{67}$ Jacobs and Potter (1998)

${ }^{68}$ Nearpass, G. R. (2003). The overlooked constitutional objection and practical concerns to penalty enhancement provisions of hate crime legislation. Albany Law Review 66: 547-573. Pg. 554.
} 
effect' argument similar to that employed by Mitchell in Wisconsin v. Mitchell when speaking about the federal hate crime act passed in 2009 Indiana Representative Mike Pence remarked that "the measure could inhibit freedom of speech and deter religious leaders from discussing their views on homosexuality for fear that those publicly expressed views might be linked to later assaults." ${ }^{, 69}$

A more extreme example of this kind of opposition could be found in South Carolina in the late 1990s which marked the period of time that state came closest to passing comprehensive bias crime legislation. A proposed bill that would have increased penalties for crimes committed against some one because of their race, ethnicity, sexual orientation or gender was referred to by Charleston area Rep. John Graham Altman III as a "pedophile protection bill.,"70 Altman reasoned that the bill meant "If a pedophile molested his granddaughter, and Altman referred to the pedophile as a pervert while hitting him, Altman said he would receive a stiffer penalty for his revenge under this legislation." 71

A less politically charged and perhaps more nuanced position that is somewhat similar to the one displayed in the quotes from Rep. Boehner makes the claim that all crimes are hate crimes. It should not matter whether or not a crime is motivated ideological hatred of a victim or victims based on their descriptive characteristics. As a result of hate crime laws, certain groups receive, unfairly, larger amounts of protection, and certain criminals receive greater punishment. If there is no alternate rationale for

\footnotetext{
${ }^{69}$ Hulse, Carl. "House Votes to Expand Hate Crime Definition." New York Times, October 8, 2009, Sec. A1.

${ }^{70}$ Graves, Rachel. “Altman Scorns Hate Bill.” The Charleston Post and Courier, March 31, 1999.

${ }^{71}$ Ibid.
} 
prosecuting some people to a greater extent than others for the same crime, other than it being based on who is victimized, a situation arises where different offenders charged with essentially the same offence are treated unequally under the law. The character of two criminals who have committed alike crimes is being what is being assessed and this goes beyond a conventional consideration of facts in the criminal case. These variations of critique have led to bias crime legislation being attacked on First Amendment, due process, and equal protection grounds. ${ }^{72}$ It is generally the more articulate arguments against bias crime legislation that maintain a focus on the constitution. While political actors will sometimes invoke the constitution, it is often done in a vague fashion. Whether supporting or opposing bias crime laws their positions often remain lodged within a heated rhetorical framework established by civil or minority rights battles.

The decisions by the Supreme Court in Mitchell and Black undoubtedly took some of the wind out of the sails of those who oppose bias crime legislation on constitutional grounds. Still, a considerable community of critics continue to attack these laws on grounds that are of a much greater depth than the arguments so often employed by conservative politicians. This can often cause the debate to veer onto philosophical ground and confront the question of whether or not hate crime laws have a place in liberal societies like the United States.

\footnotetext{
${ }^{72}$ Nearpass, G. R. (2003).
} 


\section{Further Debate in the Literature}

\section{Surrounding Bias Crime Law}

While not being the only approach taken towards invalidating hate crime laws, it is made clear through the case history, that the arguments against bias crime laws and legislation are primarily based in the perspective that they constitute a violation of the First Amendment. ${ }^{73}$ In this view, pure hate speech laws are clearly unconstitutional. The federal and state governments cannot engage in favoring the content of certain forms of speech over others, at least not to the point of criminalizing speech, no matter how abhorrent it may be. This was basically the position adopted by the majority of the Court R. A. V. v. St. Paul, Minnesota and it effectively eliminated the possibility of hate speech laws like those often found in other western democracies. Despite the Supreme Court's acceptance of penalty enhancements in Wisconsin v. Mitchell, when hateful speech or motivation is attached to existing criminal conduct some still find bias crime laws just as constitutionally objectionable as hate speech laws. Even if the Court has developed the jurisprudential reasoning with which to justify punishing bias motivation in crime, critics of these laws still feel that such a justification conflicts with the liberal spirit of the First Amendment.

Understandably, the oppositionist position in relation to bias crime laws is made more complicated than opposition to hate speech regulation because it is attached to

\footnotetext{
${ }^{73}$ However, the First Amendment approach is not the only one employed in attempting to invalidate hate crime laws. For example, Nearpass (2003) takes what could be deemed a more novel stab at arguing against penalty enhancements by using the Fifth Amendment and the double jeopardy clause. Others constitutional objections to bias crime legislation have taken up due process and equal protection, such as Apprendi. Still, the opposition has most often been centered on the First Amendment. Certainly, the perspectives this piece will measure through the media whether Neutral, Positive, or Negative revolve around the First.
} 
something already widely accepted as prosecutable. First Amendment jurisprudence provides plenty of evidence that, given the proper circumstances, speech can be curtailed or prosecuted and some content is threatening enough to warrant suppression. For example, this can be seen in the outlining of 'fighting words' in Chaplinsky v. New Hampshire, ${ }^{74}$ as well as Miller v. California giving states the ability to develop community standards as they relate to obscenity, ${ }^{75}$ or New York v. Ferber allowing for exceptional broadness in the creation of child pornography laws. ${ }^{76}$ The Supreme Court has determined that bias crime represents a First Amendment exception similar to the actions at issue in these cases. The Court decided in Mitchell that the speech element within bias crime law can justifiably result in a penalty enhancement because it contributes to a relevant threat beyond the act itself.

Many of the constitutional arguments in Mitchell and $R . A . V$. that opposed bias crime laws can still be seen in the contemporary political and academic rhetoric. Conservative and classically liberal figures still claim that these laws have a 'chilling effect' on speech, allowing the state to create favored categories of speech and punish other forms, and entail the punishment of thoughts character traits. Such objections have not been completely abandoned, but arguments have understandably been modified in order to find new angles of critique. In the years following Mitchell, some of those opposed to hate or bias crime legislation have focused on framing these laws as extraordinary in their attack on the ideas, thoughts, or the character of the accused in bias crime cases. An attempt has been made to draw a line between the constitutional and

\footnotetext{
74 Chaplinsky v. New Hampshire, 315 U. S. 568 (1942).

${ }^{75}$ Miller v. California, 413 U. S. 15 (1973).

${ }^{76}$ New York v. Ferber, 458 U. S. 747 (1982).
} 
legal exceptions that were made as a result of the circumstances at issue in cases like Chaplinsky, Miller, and Ferber and those exceptions inherent in hate crime laws.

Hurd adopts such an argument, at times quite compellingly, by claiming that bias crimes are prosecuted in a novel fashion from other crimes. She contends that hate and bias crime legislation "has worked important changes in both our criminal law doctrine and our political presuppositions" and that "no longer is character immune from criminal sanction; no longer is virtue and vice outside the scope of state action." ${ }^{.77}$ Hurd feels that an approach to criminal prosecution has taken on a uniquely normative quality within bias crime legislation; a normative quality in her view not found in previous legal precedence. She delves into a social philosophical realm by comparing the use of bias crime laws as a piece of a "perfectionist agenda," warning that legislators "must be confident that in enacting such legislation, they are not inhibiting the liberty to be bad that is necessary to the cultivation of good." ${ }^{, 78}$ Hurd is sympathetic to the stated goals of bias crime legislation, but still seems to feel there is a real possibility that it can have the effect of suppressing valuable public debate, much in the same way that the criminalizing of simple hate speech would theoretically lead to the reduction of valuable public dialogue. Hurd concludes her argument against bias crime legislation by warning that, while the results of bias crime laws will likely fall in line with commonly held values, a burden remains with the state to "assure us that they will exercise only what is diseased." 79

\footnotetext{
${ }^{77}$ Hurd, H. M. (2001). Pg. 232.

${ }^{78}$ Ibid. Pg. 231.

${ }^{79}$ Ibid. Pg. 232.
} 
These legal and philosophical critiques are not wildly off-base or irrational like much of the more politically driven opposition can be. There is undoubtedly a normative component to the existence and construction of bias crime legislation. It is inherent in its speculative expressive function. The question then becomes: is this normative element especially unique and perhaps more importantly, a serious threat to the legal and constitutional rights of United States citizens? Kahan counters Hurd by acknowledging that while one can make the argument that it is "wrong to view the values expressed by hate crimes as any worse than those involved in other types of crimes," critics have no basis for the claim that "hate crime laws are bad because they take values into account in a way that the rest of the law does not." ${ }^{80}$ He sees the role that values and assessing harm play in bias crime legislation as being little different than that at work in "homicide gradations, rape law, capital sentencing provisions, and a host of other doctrines." 81 The line drawn between bias and other crimes, and the attack on the normative quality of bias crime law, is owed, according to Kahan, to the norms informing bias crime being "nontraditional and contested." 82 Ultimately, he sees the normal framework for debate being skewed by an adherence to "orthodox liberal theory," and that the "legitimacy of such laws" should not depend "on whether they deter harms independent of the state's aversion to hate criminals' noxious ideologies." ${ }^{83}$ In Kahan's view, the idea that other areas of criminal law have fallen within these guidelines is inaccurate.

\footnotetext{
${ }^{80}$ Kahan, D. M. (2001). Pg. 183.

${ }^{81}$ Ibid. Pg. 192.

${ }^{82}$ Ibid. Pg.

${ }^{83}$ Ibid. Pg.
} 
The view of Altman perhaps lands somewhere in the middle of Kahan and Hurd. Like Kahan, he feels that the debate surrounding bias crime laws is generally flawed; that the "vision of a clear and simple answer to the issue" of hate crime legislation is "illusory." ${ }^{84}$ In what could be deemed at least minor agreement with many of the critics of bias crime laws, Altman does acknowledge that they infringe on the principle of freedom of thought. Employing the philosophical concept of 'public reason' he argues that bias crime laws most appropriately find justification in the need for equitable citizenship. Some, of course, argue that the opposite is the result of bias crime legislation and these laws actually damage the ability to realize such a goal because they isolate certain groups for protection. Altman counters this by writing that "if we lived in a social world where individuals were not vulnerable to second-class status on account of such factors as race, gender, and sexual orientation, then bias crimes might still exist but they would not contribute to...systematic consequences.. ${ }^{85}$ However, that is not the reality. From the perspective of public reason it is acceptable to attempt to get from here to there by employing bias crime protections along the lines which now exist. If American society were at a more equitable point the fear of traditionally marginalized groups becoming favored would perhaps be relevant. As it stands now such a concern is largely unfounded.

Altman's approach ultimately reads as a very eloquent articulation of the expressive and instrumental goals invoked by many advocates with, perhaps, the added benefit of a more reasonable acknowledgement that the liberal First Amendment values that hate crime laws encounter cannot be easily shrugged off. The philosophical

\footnotetext{
${ }^{84}$ Altman, A. (2001). Pg. 173.

${ }^{85}$ Ibid. Pg. 171.
} 
reasoning as laid out by Altman and Kahan, along with the constitutional arguments that have proved persuasive in prominent Supreme Court cases, and the political advocacy both in the literature and on the part of politicians have all provided the groundwork for the passage of many hate crime statutes in a clear majority of states. Their passage has also understandably coincided with a general popularity amongst the citizens of these states. Undoubtedly, despite some persistent objections, bias crime legislation has become a part of our liberal society and it is hard to imagine it will be successfully removed from the many states that employ it, or at the federal level. Still, how successful has bias crime legislation been, or, more central to this piece, how effective have the expressive or messaging aspects of hate crime laws been? Once the laws are passed, are hate crimes more openly and frequently addressed, and are bias crime laws viewed by the public as an effective and successful means of government fostering a more equitable and cohesive society? Most central to this piece is the question of whether or not this is reflected and can be measured by looking at the media.

Before moving on to the research pertaining to the state level which will address these questions, it is of value to review how they vary in their approach to bias crime legislation and examine why these variations exist. Every state has approached the construction of bias crime laws in at least somewhat unique fashion, and a few state legislatures have avoided the creation of such laws altogether. Special attention will be paid to the four states of Washington, Minnesota, South Carolina, and Wyoming. The states featured in the subsequent content analysis. 


\section{Chapter 3:}

\section{Bias Crime Laws and Their Variations at the State Level}

Every state is subject to some bias crime legislation due to its passage at the federal level. However, this means that the resulting laws only apply to crimes that fall under federal jurisdiction, which leaves out a considerable majority of offenses. The first major piece of legislation related to hate crimes passed at the federal level was the widely supported Hate Crime Statistics Act enacted by the $101^{\text {st }}$ Congress. This bill required the Justice Department to compile and publish statistics regarding crimes based on race, religion, sexual orientation, and ethnicity. National origin, gender, and disability were added as statistical categories in 1994 with passage of the Hate Crime Sentencing Act which also increased penalties for bias motivated crimes committed in national parks and on other federal property. It would take another fifteen years for another major piece of legislation directly aimed at bias crime to pass. Still, in the intervening years laws that bore some relationship to hate crime were passed, such as a 1994 Violence Against Women Act, and legislation increasing federal jurisdiction and increased penalties for church burnings. ${ }^{86}$

In 2009 , after roughly a decade of attempts to expand federal hate crime laws, the Matthew Shepard and James Byrd Hate Crimes Prevention Act was passed as an attachment to a Defense Department authorization bill. This latest piece of federal bias crime legislation expanded to the prosecution of crimes based on the victim's actual or perceived sexual orientation, gender, gender identity, or disability. It also increased the

\footnotetext{
${ }^{86}$ Timelines and other material found at the Anti-Defamation League website http://www.adl.org and the Human Rights Campaign website http://www.hrc.org. Accessed on April 5, 2011.
} 
ability of federal authorities to intercede in states with limited bias crime laws.

Additionally, it provided greater federal resources for local law enforcement in the area of hate crimes. ${ }^{87}$ Despite the expanded federal capabilities of the federal government put in place with the 2009 Hate Crimes Prevention Act, avenues available for addressing bias crime in states with few or no laws remain very limited. Like much criminal law, the emphasis and prosecution of bias crimes is still primarily handled at the state and local levels.

The kind of bias motivated acts legally targeted outside of federal jurisdiction varies from state to state. The broad descriptive categories most often covered by bias crime statutes and penalty enhancements are race, ethnicity, and religious affiliation. Currently forty-five states and the District of Columbia cover these groups with bias crime measures. Less prominent are statutes aimed at punishing crimes as they relate to sexual orientation, gender, gender identity, and mental, physical, or sensory disabilities. However, increasingly, these latter categories have been addressed and many of them are covered by a majority of states. For example, thirty-two states increase penalties for crimes aimed at sexual orientation. Thirty-two also include disability, and twenty-eight states count gender as a protected category. ${ }^{88}$

There are also varied forms of laws that are aimed at protecting these groups from hate crimes and highlighting such crimes when they occur. Not surprisingly, the most common of these are penalty enhancement provisions for bias crimes similar to the law at issue in Wisconsin v. Mitchell which the Supreme Court found to be decidedly

\footnotetext{
${ }^{87}$ Ibid.

${ }^{88} \mathrm{http}: / /$ www.adl.org/99hatecrime/state_hate_crime_laws.pdf. Accessed on April 5, 2011.
} 
constitutional. Forty-five states and D.C. have penalty enhancements for bias motivated crimes. As noted above, all of the states with penalty enhancements address crimes relating to race, ethnicity, and religious affiliation, but vary according to other categories. The type of crimes that the penalty enhancements are applied to range from assault or malicious harassment to bias motivated acts of vandalism and property damage. Within this latter category, many states have created laws that directly address bias crime based on religious affiliation by fashioning statutes that criminalize interference with, vandalizing, or damaging places of religious worship. This can also serve to protect places of worship in their capacity as community centers or rallying points which have often been subject to attack based more on racial associations than religious ones. ${ }^{89}$

Many states, as diverse as Connecticut, Florida, and Washington have specifically associated the burning of crosses with criminal action. However, the way in which the use of symbols is criminalized can vary. In Connecticut the use of a burning cross is deemed prosecutable as a "deprivation of rights" through the "desecration of property.",90 This law covers public property and private property without the written consent of the owner, thus leaving the kind of private cross burning activity at issue in Virginia $v$. Black theoretically legal in Connecticut. In Washington the burning of crosses is categorized as a form of malicious harassment, or essentially a form of intimidation, which makes it similar to the kind of regulation in the Virginia law at issue in Black. ${ }^{91}$

Laws providing easier access to procedures for the filing of civil actions against the perpetrators of hate crime are also a frequent form of legislation existing in thirty-two

\footnotetext{
${ }^{89}$ Ibid.

${ }^{90}$ Chapter 814c, Section 46a-58.

${ }^{91}$ Washington State Law RCW 9A.36.080.
} 
states and D. C. A common example of such a statute can be found in Minnesota, which states that "a person who is damaged by a bias offense has a civil cause of action against the person who committed the offense. The plaintiff is entitled to recover the greater of: (1) $\$ 500$; or (2) actual general and special damages, including damages for emotional distress." 92

Another form of hate crime statute seen in just over half of U. S. states involves mandating the collection of data on bias motivated crimes. However, the kind of data collected can vary from state to state. For instance, out of the twenty-eight states with data collection statutes only sixteen require collecting sexual orientation centered hate crime data, and only twelve collect data on hate crimes involving gender. Again, using Minnesota as an example, these kinds of measures entail that "a peace officer must report...every violation... if the officer has reason to believe, or if the victim alleges, that the offender was motivated to commit the act by the victim's race, religion, national origin, sex, age, disability, or characteristics identified as sexual orientation." $" 93$ The Minnesota statute then goes on to require the detailed cataloging and recording of the biased crime. Beyond these data collection measures simply ensuring that an accurate tally of bias crimes is gathered, they theoretically motivate police officers to pay greater attention to the possible role of bias motivation in crime because it is required by law. This can aid in the state signaling to its citizens through more than political rhetoric that authorities are paying close attention to crimes that may go beyond the initial victim and indicate a pattern in the kind of ill treatment a particular group is receiving.

\footnotetext{
${ }^{92}$ Minnesota statute 611A.79.

${ }^{93}$ Minnesota statute 626.5531.
} 
Even more relevant to these objectives just mentioned, as well as making bias crime laws effective, but more rare than data collection legislation, are statues mandating or requiring law enforcement training in relation to hate or bias motivated crimes. In fact, only fourteen states, including two researched in this project (Washington and Minnesota), require such training. Naturally, training statutes are meant to provide police with the necessary tools to ensure that other hate crime laws, statutes, and measures are applied at the law enforcement level in the manner in which they are intended. In a state like Minnesota, training along these lines is even mandated, though not required, for prosecutors. Presumably, this is meant to maintain proper and efficient application of bias crime laws along their entire path from the street to the court room.

Every state and the District of Columbia, with the exception of Wyoming, have some form of law that could be categorized as combating bias crime. Many states have passed an extensive collection of measures that cover a wide array of descriptive characteristics that can make individuals or groups subject to bias attack, while others have passed limited but significant legislation. A much smaller number of states have passed a handful of measures that can be stretched or construed as possibly related to bias crime. However, they are not utilized in this fashion, which makes their response to hate crime little different than that of Wyoming. South Carolina, Arkansas, Georgia, and Indiana could all be categorized in a similar manner to the one state with absolutely no hate crime related legislation. Being included in a category similar to Wyoming is appropriate due to these four states having no laws that create any kind of penalty 
enhancement for bias offences, cover any specific group traditionally made the target of such crimes, or even mention bias or hate crime.

Because of this the laws that can be somewhat related to hate crime in South Carolina, Arkansas, Georgia, and Indiana do little in a practical sense to allow the government to prosecute bias crime as such, and theoretically do even less in an expressive sense. For example, in South Carolina, one of the states featured in this project's content analysis, bias crimes can be prosecuted, but under statutes that relate to a generic violation of civil or constitutional rights. Institutional vandalism such as the property destruction of churches and other places of worship is also covered in a general fashion. ${ }^{94}$ Technically these laws could be used to combat what can be categorized as hate crime, and seemingly the passage of a law focused on church vandalizing provides some acknowledgment of a historically common form of hate crime. However, the laws never directly address bias crime as a concern, and there are certainly no penalty enhancements as a result of bias motivation. Even if a bias crime is prosecuted by the use of these laws it is never legally acknowledged as a bias or hate crime. There will therefore be no penalty enhancement, but perhaps more importantly, the declaratory value of the South Carolina laws is essentially nonexistent.

Elaborating on polar opposite states, such as Minnesota and South Carolina, is not meant to suggest that states either have vast amounts of hate crime legislation or virtually none. For instance, at first glance the state of Utah could perhaps be viewed as being on par with South Carolina, and the other states mentioned above with basically no laws but, while it only has one law related to bias crime, there is a notable distinction to be drawn.

\footnotetext{
${ }^{94}$ South Carolina Statutes 16-5-10, 16-17-560, 16-11-535, and 16-11-110.
} 
The one bias crime statute in Utah was added to an existing law generically addressing constitutional and civil rights, but it directly addresses hate crime and also involves a penalty enhancement for multiple categories of descriptive targets. ${ }^{95}$ These last two elements of the Utah law and its amendments remove the state from the category of those still largely resisting bias crime legislation, even without an amount of laws that matches the extensive coverage of many other states. More generally, what can be viewed as a sort of moderate approach to bias crime law is characterized by states with at least some legislation directly addressing bias crime, while at the same time having a limitation on the types of groups protected by laws. Moderate states might also have no requirement for data collection, they often lack of access to civil action procedures or damages as the result of a bias act, and frequently such states do not require training for police regarding hate crimes.

\section{Why Are There Variations?}

The reasons for a state like California having nineteen statutes that could be characterized as bias crime related ${ }^{96}$ and a state like Wyoming having none cannot be explained by looking at any one factor. At the most superficial level it could appear as though an abundance or lack of bias crime legislation could be owed to the amount of bias crime a state is faced with. For example, according to the FBI, the amount of reported hate crimes in Wyoming rarely amounts to more than ten in a given year.

\footnotetext{
${ }^{95}$ Utah Statute 76-3-203.3.

${ }^{96}$ http://www.partnersagainsthate.org/laws/list-of-hate-crime-laws.html?state=ca. Accessed on April 7, 2011.
} 
Further, the majority of reported hate crimes are still based on race or ethnicity. ${ }^{97}$ So, a state with a limited amount of diversity might not deal with a large amount of bias crime and not feel the need to create legislation accordingly. However, crimes that can reasonably be categorized as being based on hate or bias are certainly not exclusive to particular locations or communities in the United States. Therefore, it would seem a stretch to posit that legislative response is simply proportional to the amount of bias crime that a given state or community is likely to encounter. Largely due to immigration, communities are increasingly plural in their makeup, and certain categories such as gender, sexual orientation, or disability have really never been exclusive to certain geographical locations. Additionally, as standards vary by community, and it is possible that states resistant to legislation will underreport bias crime, ${ }^{98}$ numbers must often be taken with a grain of salt. Still, even with the numbers as they are, a brief glance at the amount of FBI-recorded incidents per year provides ample evidence that legislation and the relative threat of bias crime often do not coincide. For example, the number of bias crimes reported in South Carolina in 2008 was merely eleven fewer than the total in Minnesota, yet the latter state is a national leader in hate crime legislation and the former has passed none. ${ }^{99}$

The politics of a given state is another factor that readily presents itself as a possible determinant of why bias crime legislation is enacted. In fact, the dominant political climate or culture of a state does appear to have an effect on bias crime law

\footnotetext{
${ }^{97}$ FBI Uniform Crime Reports, found at: http://www.fbi.gov/about-us/cjis/ucr/ucr. Accessed on April 7, 2011.

${ }^{98}$ King, R. D., Messner, S. F., \& Baller, R. D. (2009). Contemporary hate crimes, law enforcement, and the legacy of racial violence. American Sociological Review 74: 291-315.

${ }^{99}$ FBI Uniform Crime Reports, found at: http://www.fbi.gov/about-us/cjis/ucr/ucr.
} 
passage. In a general sense, a glance at states with a large amount of bias crime legislation and those without does show certain trends relating to political ideology. The national popularity of bias crime legislation has ensured that widespread passage of laws has not occurred only in states like California, Minnesota, or Washington, which tend to skew towards more Democratic driven progressive politics, even if these were the states that pioneered the passing of hate crime laws. Indeed, some states with a more conservative political culture such as Texas and Nebraska have passed extensive hate crime legislation. However, those states with decidedly small amounts of bias crime laws or virtually none do tend to be politically conservative and generally have Republicandominated legislatures. This is not to imply that support or opposition always falls along party lines, but evidence suggests that they can work as an at least reasonably accurate predictor of support for bias crime legislation. In fact, previous research has found that the percentage of a state legislature that is Democratic has a strong statistical relationship to the adoption of hate crime legislation. ${ }^{100}$ Such an outcome is theorized as being most likely a result of the Democratic Party having a stronger political bond with, and generally acting more favorably toward, the minority groups that are most often the victims of bias crimes and thus the focus of bias crime laws. ${ }^{101}$ The party affiliation factor even proved to be a stronger indicator over time, perhaps as both parties

\footnotetext{
${ }^{100}$ Soule, S. A. \& Earl, J. (2001). The enactment of state-level hate crime law in the United States: intrastate and interstate factors. Sociological Perspectives 44, 3: 281-305.

101 Ibid.
} 
increasingly solidified their position on a form of legislation that was relatively fresh when researchers first began looking at how it was affected by political parties. ${ }^{102}$

Another factor that has been found to be relevant to the passage of bias crime laws is past policy innovation, at least with the states that were at the forefront of passing extensive legislation. It has also been found that states that devote a large amount of media attention to hate crimes are more likely to pass hate crime legislation, ${ }^{103}$ which is of particular relevance to this piece. If media coverage indicates a greater likelihood of passage, this same coverage would theoretically remain consistently high after passage when compared to media attention in communities with no laws. Further, it would perhaps even increase the amount of coverage, since bias crimes continue to occur at similar levels after the passage of legislation. ${ }^{104}$ Attention directed at bias crime has been entrenched within the legal system, and this would be reflected in the media.

The importance of media coverage in the creation of laws also lends evidence to the notion that in states where "the social problem of hate crime is most evident" laws are enacted at a higher rate. ${ }^{105}$ Thus, issue salience may have just as much, if not more, bearing on whether or not bias crime legislation is passed, and it often has little relation to how many bias crimes have occurred. Essentially, the amount of hate crimes reported statistically in a given year or over a period of time will very likely not have a profound effect on media reporting, but larger or more dramatic bias crimes can have a

\footnotetext{
102 Jenness, V. \& Grattet, R. (1996). The criminalization of hate: a comparison of structural and polity influences on the passage of "bias-crime" legislation in the United States. Sociological Perspectives 39, 1: 129-154.

${ }^{103}$ Soule \& Earl (2001).

${ }^{104}$ FBI Uniform Crime Reports, found at: http://www.fbi.gov/about-us/cjis/ucr/ucr. Accessed on April 5, 2011.

${ }^{105}$ Ibid. Pg. 294.
} 
disproportionate effect. It has been theorized that issue salience, media coverage, and the passage of hate crime laws is much more affected by 'triggering' events or high profile bias crimes rather than overall numbers. ${ }^{106}$ Theorizing about the effects of 'triggering' crimes again provides an example of the expressive qualities surrounding both hate crime and the legislation meant to combat it. Smaller bias crimes can occur in large numbers but still not approach the message effects on the public consciousness of larger and generally more violent crimes. Seemingly, one high profile and well publicized hate crime has a more profound effect on how bias crime is handled politically than does many smaller bias crimes in aggregate. Subsequently, a high profile crime can create a sense of public urgency even if, in reality, bias crimes are not occurring with a great deal of frequency. Of course, the relationship between issue salience and media coverage is not exclusive to the area of bias crime, but it does appear to have been especially relevant to the promotion and successful passage of bias crime legislation in recent decades. The idea that issue salience is tied more to the perception of a mounting problem rather than the actual number of crimes is later looked at through a comparison of the research in this project regarding media coverage of bias crime and FBI statistics.

\footnotetext{
${ }^{106}$ Jenness \& Grattet (1996). Pg. 148.
} 


\section{Chapter 4:}

\section{Profiles of Content Analysis States}

\section{Washington and Minnesota}

The passage and character of bias crime legislation in the State of Washington has already been touched upon numerous times in this piece, but a little more background should be given before moving on to a content analysis of its media. Like many other relatively progressive states, Washington began to craft a series of bias crime measures in the early 1990's around the time the Supreme Court cases of R. A. V. v. St. Paul, Minnesota and Wisconsin v. Mitchell helped to provide guidelines for their construction. In 1993, Washington passed a law increasing penalties for what is termed 'malicious harassment' based on the victim's 'real or perceived race, color, religion, ancestry, national origin, gender, sexual orientation, or mental, physical, or sensory handicap.”"107 In 2009, this was expanded to include protections for transgendered individuals and groups, or gender identity. The malicious harassment law is a unique, broadly constructed cornerstone-like measure addressing bias motivated acts that serves to cover a variety of crimes which range from physical injury or assault to property damage. The delivery of threatening messages to individuals or groups, and how this can be communicated through a variety of means is also covered, including special mention of the symbolic use of cross burnings and swastikas. The use of these two symbols on the property of an African-American or Jewish citizen, respectively, is taken as prima facie evidence of biased harassment or intimidation. This provision is similar to the prima facie element struck down in Virginia $v$. Black, but is saved constitutionally by stating that the use of

\footnotetext{
${ }^{107}$ Washington State Law RCW 9A.36.080.
} 
these symbols has to be clearly directed at an individual or a group. The Black law assumed that any cross burning was done with the intent of biased intimidation, and that was deemed overly broad.

Washington State has a law protecting places of worship from bombing and property damage which indirectly can be viewed as a bias crime law. It has also passed laws requiring law enforcement training in the area of bias or bigoted malicious harassment, a statute requiring data collection in relation to such crimes, and specific channels through which to seek civil restitution as a result of biased crime victimization.

Like Washington, the state of Minnesota has already been used as an example often in this piece, but a few more details might prove illuminative. Minnesota was the setting for the Supreme Court making clear that laws bordering on criminalizing hate speech would be deemed unconstitutional in $R$. A. V. As the St. Paul ordinance at issue in this case would imply, Minnesota was ahead of much of the country in constructing laws addressing bias motivated crimes. In 1989, laws were passed increasing penalties for physical assault, property damage, and harassment or intimidation based on race, color, religion, sex, sexual orientation, disability, age, or national origin. As was mentioned previously, Minnesota has also passed the various laws that accompany or compliment extensive bias crime penalization and broad group protection, such as those covering law enforcement training, civil redress, and data collection.

The passage of extensive legislation regarding bias or hate crime in Minnesota and Washington State was not done without any kind of opposition, but both states passed the basic laws and penalty enhancements quickly following the introduction of 
bills into their legislatures. Seemingly, the more progressive and Democratic controlled political cultures of both states were receptive, or perhaps susceptible, to the immediacy surrounding hate crime that arose in the 1980s and 90s. This is exemplified by the findings attached to Washington State's passage of their malicious harassment law which were quoted earlier in this piece. These findings essentially mirrored the tone of hate crime law advocates. As the research conducted for this project will later show, this emphasis on or concern regarding bias crime has particularly increased when viewing media in the State of Washington.

The other two states profiled in this project's content analysis, South Carolina and Wyoming, have had a much more complicated relationship with proposed bias crime legislation. The lack of ease with which such measures have found passage in these two states could be viewed as reflective of their respective political cultures. In looking at these next two states it is worth keeping in mind that there might be an expressive actualization or message inherent in not passing hate crime laws. The message sent by not passing legislation can perhaps be as effective for the opposition consensus of the Wyoming and South Carolina state legislatures, as the message imparted through passing laws can be for the legislature in states like Minnesota and Washington.

\section{South Carolina}

As was previously mentioned, the state of South Carolina has passed laws aimed at institutional vandalism which could be interpreted as means to address some acts of bias crime, but the state has passed no laws directly addressing the subject. In the mid- 
nineties there was a push spearheaded by then governor David Beasley largely as the result of some high profile bias crimes around that time. ${ }^{108}$ Through the latter part of the decade more progressive and moderate members of the South Carolina legislature continued attempts to pass a penalty enhancement provision for bias crimes to no avail. In keeping with the expressive nature of such legislation, sponsors of the bias crime bills seemed to be aware of the need to address the history of the state and that region of the country, as well as to join the rest of the nation in openly condemning hate crime. For example, a Democratic Representative named Doug Jennings, who cosponsored a hate crime bill in 1999, commented that South Carolina needed to pass the bill to show that they "frown upon that kind of crime in a more serious manner." ${ }^{109} \mathrm{He}$ also added in reference to a penalty enhancement statute that "even Mississippi has one."110 Interestingly, the debate over hate crime legislation coincided with political battles over the confederate flag's prominence on the state capital. The two issues were often lumped together as a battle between traditionalist supporters of the political status quo in the South and those who wished to acknowledge problematic race relations in South Carolina's history and take more of a progressive stance. Still, despite there being many members of the South Carolina legislature that were vehemently opposed to the passage of any form of bias crime legislation it may have been the inclusion of sexual orientation and gender as protected groups that was most objectionable to more conservative politicians. If the legislation had been limited to those groups most

\footnotetext{
${ }^{108}$ Heilprin, John. "Beasley Order Carries No Weight" The Charleston Post and Courier, November 3, 1996.

${ }^{109}$ Graves, Rachel. "Hate Crimes Bill Killed in House Committee" The Charleston Post and Courier, March 5, 1999.

${ }^{110}$ Ibid.
} 
conventionally included, like it was in many other more socially conservative states, it likely would have passed. ${ }^{111}$ Throughout the last decade the push for bias crime legislation in South Carolina has effectively died off and in the most recent gubernatorial race both the Democratic and Republican candidates were opposed to pressing for or even supporting the creation of hate crime laws. ${ }^{112}$

South Carolina is not alone in its resistance to hate crime legislation amongst southern states. Both Arkansas and Georgia also have, for all intents and purposes, no laws. This is not to imply that only southern state legislatures have remained resistant to the passing of bias crime laws. Many states in other regions have also passed few laws, and Wyoming and Indiana remain just as free of bias crime legislation as these three southern states. It is also worth pointing out that Florida and Louisiana have enacted relatively extensive hate crime measures, not just when compared to the South, but to the entire nation. Still, the South represents perhaps the most consistent pocket of opposition to bias crime legislation. To put this in perspective, Alabama, Mississippi, North Carolina, and Tennessee have passed penalty enhancements for some bias crime, but they join the three aforementioned southern states with no laws in not having mandated data collection or the law enforcement training which aids in making the enactment of legislation effective. Additionally, Virginia, Alabama, and Kentucky have not passed legislation covering gender. Finally, Alabama, Mississippi, North Carolina, Virginia, and

\footnotetext{
${ }^{111}$ Heilprin, John. "Gay Rights Doomed Hate Crimes Bill.” The Charleston Post and Courier, July 20, 1997.

${ }^{112}$ Behre, Robert. "Q \& A with Nikki Haley and Vincent Sheheen" The Charleston Post and Courier, October 18, 2010.
} 
West Virginia hate crime laws do not cover sexual orientation or gender identity. ${ }^{113}$

Again, many other states share similar categorical gaps and do not cover training and data collection, but there is a noticeable concentration in the South.

Regretful treatment of minority groups has by no means been restricted to one particular area of the United States. However, fairly or unfairly, it is difficult not to have the southern states' relative lack of bias crime legislation make an impression due to the overriding impression of its history. One can see this being referenced in the previous quote by the South Carolina Representative wishing to send a message through bias crime legislation about where the state currently stands in relation to its past, and being frustrated by another state (Mississippi) with a similarly bad historical reputation appearing more enlightened.

The tumultuous history of the South in the area of minority treatment, and how this relates to the current political climate and its effects on the instituting, as well as the enforcement of hate crime legislation have previously been the focus of research. One of the most interesting pieces of research found that "contemporary hate crime policing and prosecution will be less vigorous where lynching was more prevalent prior to $1930 . " 114$ This project, involving all of the southern states mentioned above with the exception of Virginia and West Virginia, was conducted based on the notion that "racial antagonism tends to be deeply ingrained in culture" and that such antagonisms evolve and manifest themselves in different ways over time. ${ }^{115}$ Subsequently, these cultural antagonisms have

\footnotetext{
$113 \mathrm{http}: / /$ www.adl.org/99hatecrime/state_hate_crime_laws.pdf

${ }^{114}$ King, R. D., Messner, S. F., \& Baller, R. D. (2009). Contemporary hate crimes, law enforcement, and the legacy of racial violence. American Sociological Review 74: 291-315. Pg. 291.

${ }^{115}$ Ibid. Pg. 292.
} 
been stoked by bias crime legislation and evidenced through "contemporary era resistance to special legal protection for minorities." ${ }^{116}$ The research in this article focused exclusively on the reporting and prosecution of hate crimes directed at racial and ethnic minorities, excluding other protected groups less historically relevant. Essentially, it looked at whether state and/or federal bias crime laws were being disproportionately ignored in southern states and concluded that "race relations have morphed from overt discrimination into skepticism about laws that assume a protective role for racial minorities." ${ }^{117}$ It seems this skepticism has not just led to the weak or nonexistent enforcement of bias crime measures, but can reasonably been seen as a roadblock to the passage of hate crime legislation in some southern states. Of course, while research linking lynching to bias crime legislation resistance highlights a fairly unique racial antagonism in the South, the states in this region are not the only ones who have resisted such laws.

\section{Wyoming}

The State of Wyoming is one of the most intriguing states when it comes to the issue of bias crime legislation. This is due to its complete lack of bias or hate crime legislation being juxtaposed with it also being home to arguably the most prominent hate crime of the last fifteen years. In October of 1998 two young men murdered University of Wyoming Student Matthew Shepard by luring him from a lounge in Laramie by pretending to be gay themselves and acting disingenuously friendly. They then drove him

\footnotetext{
116 Ibid. Pg. 293.

${ }^{117}$ Ibid. Pg. 310.
} 
to a secluded area outside of town, tied him to a fence post, beat him severely, and then left him there to die. ${ }^{118}$ The murder of Matthew Shepard received widespread national attention and this attention has carried long enough for his name to be attached to the most recent piece of federal hate crime legislation passed in 2009.

In the years preceding Matthew Shepard's death, legislation had been introduced into the Wyoming state legislature seeking enhanced penalties for bias motivated crimes. This was first done in the early 90's and attempts had been made throughout the decade resulting in little headway. Prior to the Shepard incident none of the bills had actually made their way to the floor for debate. ${ }^{119}$ However, following the local reaction and national attention brought on by such a brutally violent crime aimed at an individual based on their sexual orientation, bias crime legislation made considerably more progress in the legislature and it reached the floor for debate in 1999. Like in South Carolina, the bill supporters in the Wyoming legislature saw its passage as an important way to "send a message that crimes that put certain groups of people in fear would not be tolerated" both for the sake of the residents in the state and as a signal to the rest of the nation. ${ }^{120}$ Somewhat surprisingly, and also similar to the problems such legislation faced in South Carolina, it was protections for the gay and lesbian communities that were thought to be the major sticking point, even though the legislative momentum the hate crimes bill enjoyed was as a result of an attack based on sexual orientation. ${ }^{121}$

\footnotetext{
118 Levin and McDevitt (2002).

${ }_{119}^{11}$ Miller, Jared. "State Avoids Hate Crime Legislation” Casper Star Tribune October 11, 2008.

120 Ibid.

121 Ibid.
} 
It may not be as pronounced as in the southern states, but the oppositional posture towards bias crime legislation and a lack of extensive group inclusion in the laws that do exist is not uncommon in the similarly Republican-driven political cultures that surround Wyoming in the non-coastal western half of the United States. For example, Montana, Idaho, South Dakota, and North Dakota do not include sexual orientation or gender identity as a protected categorization in their bias crime laws. Additionally, Colorado, Kansas, Montana, North Dakota, South Dakota, and Utah do not require or mandate data collection or law enforcement training. ${ }^{122}$ Still, the holes in bias crime legislation in this part of the country are not as consistent as in the South, and many states appear to be moving in the direction of increasing hate crime laws. Even in Wyoming the Democratic Party, though consistently the minority party in the state legislature, continues to push hate crime legislation as a major element of their platform. ${ }^{123}$ It is also perhaps a sign of movement in the direction of accepting some progressive policies that the Wyoming state senate recently refused to pass a bill which would have banned the recognition of out of state gay marriages. ${ }^{124}$ This is particularly true, when taking into account that the latest elections resulted in the largest Republican majority in ninety years and thus the legislature was expected be, and in many other areas was, decidedly conservative. ${ }^{125}$

The brief profiles of these four states and their different paths or obstacles to the passing of bias crime legislation should serve to create a sense of what the media was covering over the periods of time observed in the following content analysis. This piece

\footnotetext{
${ }^{122} \mathrm{http}: / /$ www.adl.org/99hatecrime/state_hate_crime_laws.pdf

${ }^{123}$ Barron, John. "Don't Forget the Party Platforms" Casper Star Tribune June 6, 2010.

${ }^{124}$ Pelzer, Jeremy. "Wyoming Senate Votes Down Anti-Gay Marriage Bill” Casper Star Tribune March 2, 2011.

${ }^{125}$ Pelzer, Jeremy. "Wyoming Senate Kills Gay Marriage Bill” Casper Star Tribune March 3, 2011.
} 
will now move on to a description of the methodology used in compiling data for the content analysis and then a presentation of the results. These results will be looked at according to each individual state and how they compare to one another. 


\section{Chapter 5:}

\section{Methodology of Content Analysis}

The media's role in issue visibility, and how this is possibly a reflection of a community's view of bias crime and bias crime related issues, is where this project wishes to focus. An analysis of media content is valuable in understanding how hate or bias crimes and the resulting laws are perceived by the public, or even if they are visible to the public at all. Most importantly, it can serve to assess what effect the expressive element of bias crime legislation, and the consistently referenced goal of messaging through hate crime laws, actually has on the public. In assessing the results of bias crime legislation having been instituted, it is also of value to view states that have avoided the passing of such laws. Thus, this project's research is aimed at two states with extensive hate crime laws (Minnesota and Washington) and two states with essentially none (Wyoming and South Carolina).

A content analysis was conducted that involved counting the overall number of articles in each state's highest circulation newspaper by searching for use of the phrase "hate crime" or "bias crime" for the period between 1997 and 2010 for all four states. The content analysis for the State of Washington's largest paper The Seattle Times extends farther back to 1992. This was done in order to assess media coverage in the state immediately prior to the passage of bias crime legislation, thus creating a picture of how The Seattle Times has covered hate crime and bias crime related issues during the entire lifespan of such laws in Washington. Similarly, the content analysis of Minnesota's largest newspaper, Minneapolis Star-Tribune, stretches back to 1989 as a means of 
capturing media coverage since the instituting of bias crime laws. Articles appearing in South Carolina's The Charleston Post and Courier are counted from 1995 on, which marks the beginning of the strongest, yet ultimately unsuccessful push to pass bias crime legislation. The content analysis of media in Wyoming is the only state in which two different papers are used. Beginning in 1997, this project utilizes the state's second largest paper The Wyoming Tribune-Eagle since data for Wyoming's largest paper Casper Star Tribune was not available beyond 2003. A time span for the state of Wyoming not encompassing the late 1990s and the murder of Matthew Shepard leaves out a considerably important hate crime story for that state and the legislative push for the passage of bias crime law that followed in its wake. This is why The Wyoming TribuneEagle was added. The content analysis of The Wyoming Tribune-Eagle is carried out until 2010, but the higher circulation Casper Star-Tribune is also used from 2003 to 2010 in order to garner a better sense of how the media has covered bias crime in Wyoming in the past decade.

While none of the time periods covered for each state are identical, all of the time periods bear relation to one another. Comparing how local media handles hate or bias crime after it has been become an issue is made easiest by looking at varying time spans. This is because the most definitive point at which the media began to cover the issue of bias crime was when it worked its way into the state legislative agenda, where it either passed (Washington and Minnesota) or was defeated (South Carolina and Wyoming).

The online archives for each paper were used along with a LexisNexus newspaper database. Articles were categorized according to whether or not they focused on a locally 
oriented bias crime story, or on a bias crime related story from another state or at the national level. These articles included reports of possible hate crimes, hate crime charges and prosecutions, articles reporting on proposed legislation and any debate surrounding it, and opinion editorials, as well as the listing or basic description of community events addressing hate crime in some manner. Letters to the editor are not counted, nor are comments relating to articles which often appeared while searching online newspaper databases. Hate crime related material that appears in blogs is excluded since this material only appears online, and theoretically does not reach the full readership or circulation of the paper. The inclusion of blogs could distort results because they are a relatively recent addition to the tools used by news services and did not exist during many of the years covered in this analysis. Additionally, not every newspaper included in this research blogs selected news stories.

Of course, the use of just one news publication does not create a complete statewide sample of all media, excludes a great deal of other print media, and perhaps does not account for some ideological differences that would most likely exist outside of the most populated regions of each state. However, this piece focused on a comparison between states, so looking at the largest outlet of local print media from each should provide a sufficient sample of variance at the level with which it is concerned.

In both South Carolina and Wyoming it is expected that there should be a rise in articles related to hate or bias crime when the debate over legislation was most prominent and then a sharp decline in articles in subsequent years as the failure to pass legislation is reflected by little media attention. The results in Washington and Minnesota should be 
more consistent, and the number of articles should be at least fairly steady if not increasing over time, the logic being that the passage of hate or bias crime legislation results in increased public or community awareness as the laws are applied to bias motivated crimes. This should then be reflected in, and is perhaps due to the amount of coverage media outlets devote to bias crime related stories. Much of this coverage will be based most clearly on the necessity in mentioning the bias motivated aspect of hate crimes as the existence of bias crime laws shape the prosecution of such crimes. However, the expected frequency of articles related to hate or bias crime in the states that have enacted bias crime legislation should not simply be the product of or contain content solely related to the reporting of individual hate crimes and their prosecution.

Though some have argued that the cataloging of hate crimes at the federal and state level, and the highlighting of hate crimes in the media when they occur, could cause a divisive reaction, ${ }^{126}$ this project assumes differently. A frequent emphasis on hate crimes in highly circulated media should provide a signal to those groups who feel threatened by such crimes that the community on the whole shares their concern and the state is in the process of directly addressing ideologies that seek to marginalize them. Such an emphasis could also prove indicative of the communities that most readily have embraced bias crime legislation as a necessary measure. The media reports on it with frequency because the state and the public are concerned about eradicating these crimes and have accepted the categorization of bias or hate crimes as just that. Much in the same way media attention aids in the passage of laws, ${ }^{127}$ coverage in the media would not

\footnotetext{
${ }^{126}$ Jacobs and Potter (1998).

${ }^{127}$ Soule, S. A. \& Earl, J. (2001).
} 
result in condemnation of hate crime laws or divisiveness. Rather, it should accompany the acceptance of such measures, particularly as the public becomes more used to them. It is expected that the content analysis will fall in line with these assumptions. Coverage in Minnesota and Washington will be more frequent, as a reflection of the messaging effects of bias crime legislation.

The articles will separate local and national, or out of state, coverage. It is important to count reprinted national stories, such as those found in the Associated Press and the New York Times. The reprinting of stories outside the state a newspaper operates within is perhaps an even stronger example of a community or public's interest in emphasizing hate crime and bias crime issues. This can be seen as an indication that a newspaper sees as relevant even bias crimes that do not affect the community of their readership, or sees as important the federal level debate over legislation. Separating local and national articles will also help when comparing FBI hate crime statistics to media reporting of hate crime. For instance, disproportionate national attention is of note if there have been numerous reported crimes within a year in a region, but the stories that the local media has reported focus primarily on the debate over federal legislation in Congress or high profile hate crimes in other areas of the country. This might serve to make such hate or bias crimes look like a remote or irrelevant phenomenon in the state and community in which the newspaper operates.

In addition to the content analysis, Federal Bureau of Investigation data between 1996 and 2009 on reported hate crime incidents in each state is utilized to track any shift in numbers over this time period. With the exception of a brief increase around the turn 
of the millennium, the total national number of hate crimes over this period of time has been essentially unmoved despite the adoption of various forms of bias crime legislation by a majority of states in the last two decades.

United States

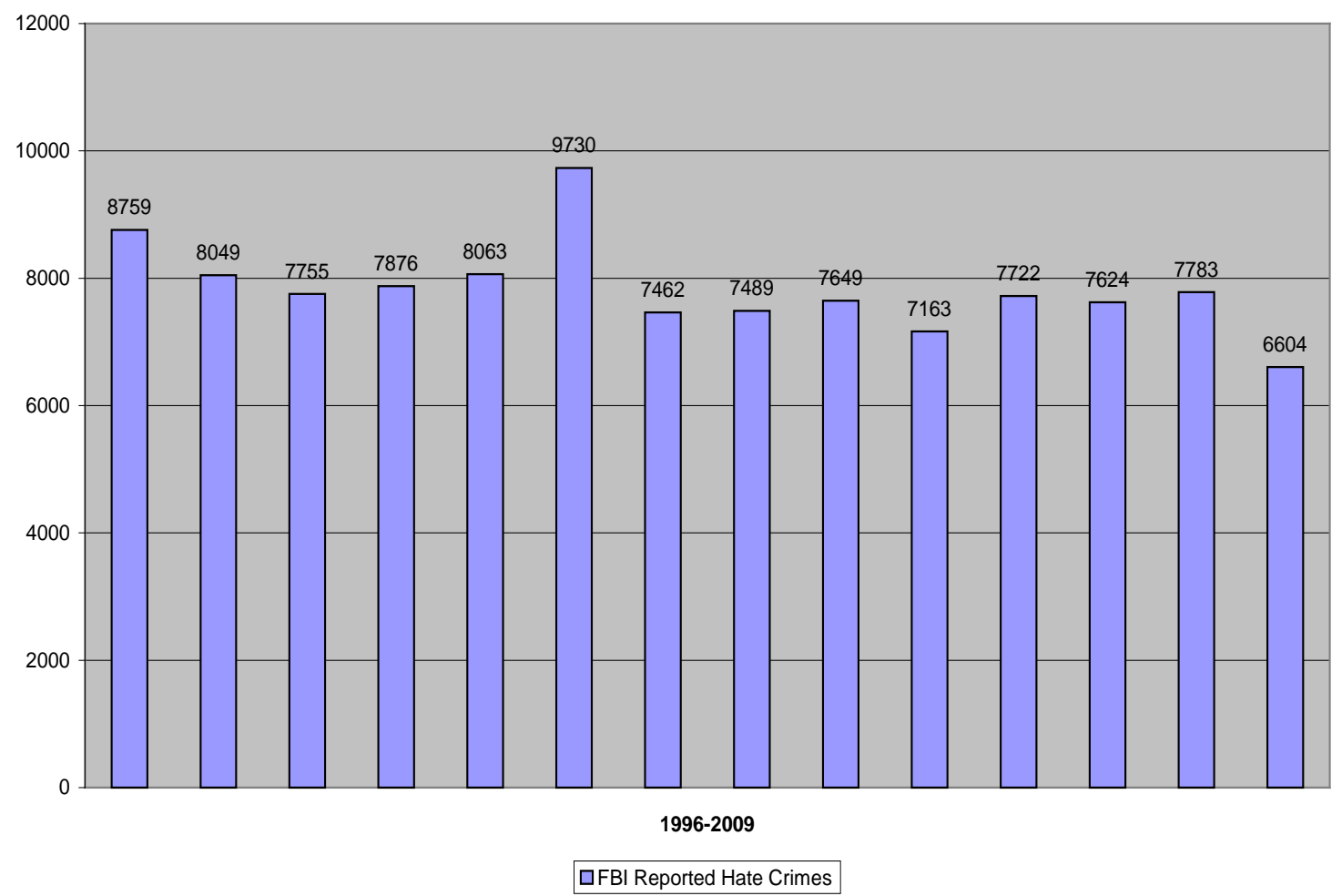

Figure 1- FBI Reported Hate Crimes in the United States 1996-2009

A brief glance at the state level numbers to see if there is perhaps any noticeable correlation between a drop in reported hate crimes and the application of bias crime laws in Washington shows that this state seems to be following the overall national trend. There have been variances in Washington, but this does not indicate that the number of bias crimes is heading in a distinct direction. This is also true for the State of Wyoming, which reports a distinctly smaller number of hate crimes than the other three states. The numbers in Wyoming can most likely at least be partially explained by the relative 
population size of the state. For much of the time period covered, the number of reported hate crimes in Minnesota was comparable to that of Washington but in recent years totals appear to be trending lower. The state that provides the most distinct trend between 1996 and 2009 is South Carolina, which has seen a rise in reported bias crimes in recent years.

Due to both the essentially consistent numbers in two of the states and an analysis of the effects of bias crime laws on overall numbers of reported crimes being outside the focus of this project, the FBI data will be primarily of value in observing how trends in the media's handling of hate crime and hate crime issues line up with the number of crimes reported. Theoretically, if the attention paid by the media to hate or bias crime stories is proportional to the existence of such crimes, there should not be much of a shift in local coverage in Washington and Wyoming. In Minnesota the number of articles would drop with the reduced number of reported hate crimes and in South Carolina, there would be an increase in local coverage in roughly the last half-decade covered by this analysis. However, it is expected that this will not be the case. Due to the nonexistence of bias crime law in the State of South Carolina, the media will print few locally oriented stories involving hate crime, despite the increased reporting of such crime by local agencies. It is assumed that coverage will not be affected by the amount of total reported crimes in any of the four states. The amount of articles in Washington and Minnesota should be consistently greater in number than that in South Carolina and Wyoming, and that number should increase over time regardless of the amount hate crimes tallied in each state by the FBI. 


\section{Chapter 6:}

\section{Results}

\section{Washington}

Of the four publications examined in this content analysis, the State of Washington's highest circulation newspaper, The Seattle Times, devoted the most coverage to hate or bias crime and the issues surrounding it. From 1992 through 2010 the overall amount of articles in a given year never dropped below 12. This was the number of articles published relating to bias crime in 1995, which marked a lull in coverage for a few years in the mid to late nineties. The lull in this period followed the considerably more frequent coverage of 1992 and 1993. The higher totals over these two years can largely be credited to the lead up to, and subsequent passage of, Washington's malicious harassment law. However, much of the overall number of articles related to bias crime in the 1990s was nationally focused, particularly in 1998 and 1999. Unsurprisingly, many of these stories were focused on the killings of Matthew Shepard and James Byrd. This had brought the attention of the entire country and led to a push by President Bill Clinton and some members of Congress to pass an expansion of federal hate crime legislation in 1999 and $2000,{ }^{128}$ which was highlighted by an attempt to expand categorization of protected groups to include sexual orientation. ${ }^{129}$

The amount of articles in The Seattle Times related to bias crime began to rise at the close of the nineties based on these prominent national stories and began reaching

\footnotetext{
128 "Murder Charges Filed in Death of Gay Student---Across Nation and in Wyoming, Calls Are Made For Stronger Hate Crime Laws.” Re-print from Associated Press October 13, 1998.

${ }^{129}$ Healy, Melissa. "House OK's Expansion of Law on Hate Crime.” Re-print from Los Angeles Times September 14, 2000.
} 
numbers similar to those seen in 1992 and 1993. This increase held into the first two years of the new millennium. By 2001, the push for increased federal hate crime legislation was effectively stalled by a new Republican administration and largely Republican Congress. Still, the level of stories focused on bias crime remained steady in 2001 when the majority of the hate crime coverage shifted and was focused locally.

Much of this local coverage involved bias motivated acts directed at Muslim immigrants from Central Asia following the World Trade Center attacks of September $11^{\text {th }}$. Most notably, there were a number of widely reported but unsuccessful attempts to damage or destroy mosques in Western Washington and a varied array of other types of harassment or assault. ${ }^{130}$ These crimes were subsequently prosecuted using either the federal penalty enhancement or the Washington state malicious harassment law. ${ }^{131}$

After the high profile local attacks following September $11^{\text {th }}$ the number of bias crime articles fell to around twenty for the next two years, which was still a higher yearly number than those found in the mid-1990s. The overall number climbed in 2004, dipped slightly in 2005, and then began a steady ascent through the rest of the decade. The climb in the overall number of articles was particularly profound between 2007 and 2010. Throughout the 2000's, the amount of articles detailing local bias crimes or local stories surrounding the issues raised by hate crime remained considerable and was virtually on par with or more numerous than nationally focused articles with the exception of the last year in the analysis, 2010.

\footnotetext{
${ }^{130}$ Ith, Ian \& Birkland, David. "Hate Causes More Sorrow: Patrols at Mosques Follow Attacks." Seattle Times September 15, 2001.

${ }^{131}$ Seattle Times Staff. "Man Pleads Not Guilty to Hate Crime Charges." Seattle Times September 29, 2001.
} 


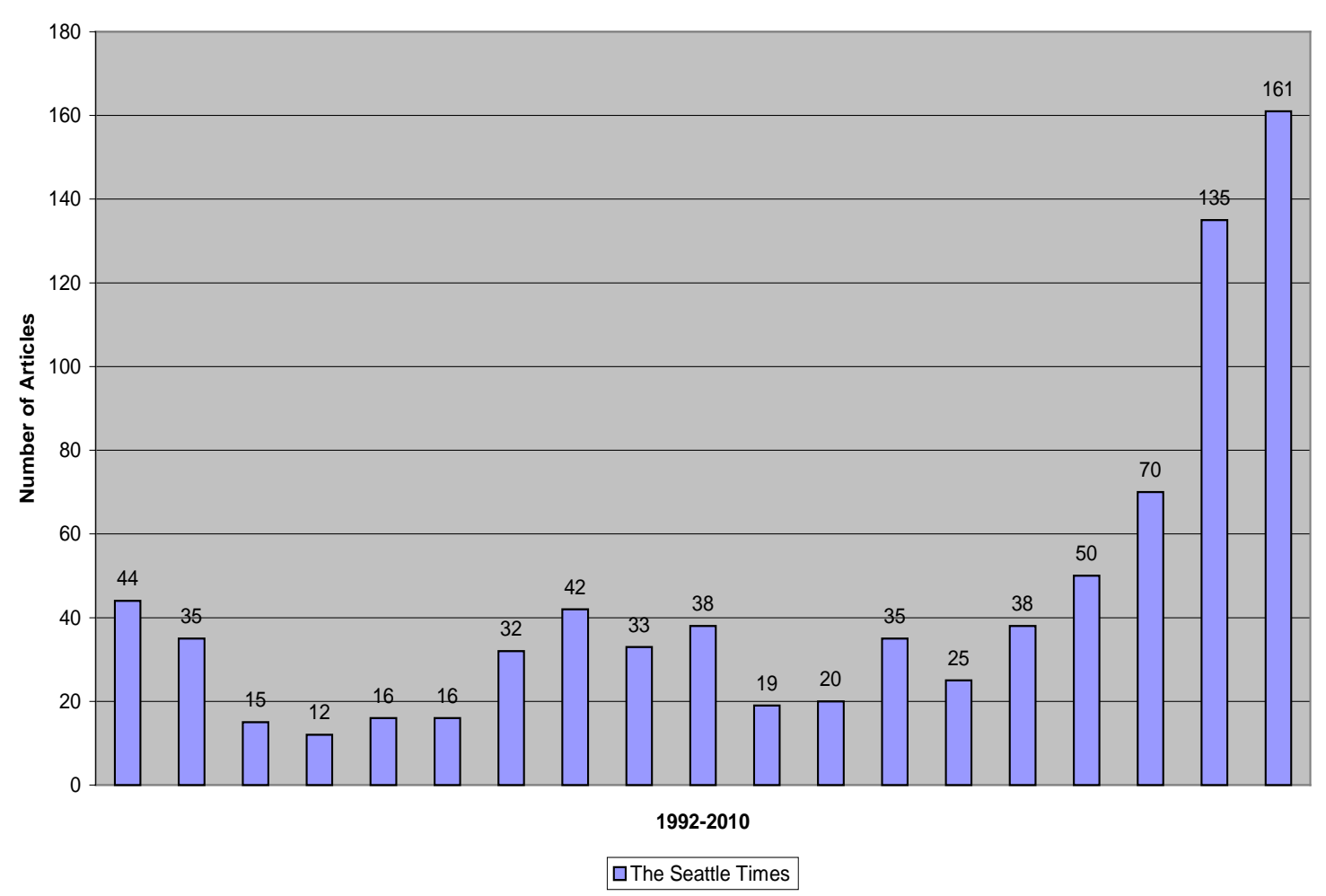

Figure 2- Bias Crime Related Articles in The Seattle Times: 1992-2010

The amount of local articles was considerably higher in 2008 and 2009. In large part, this was due to a single crime being prosecuted using the malicious harassment law. In 2006, a man named Naveed Haq entered the offices of the Jewish Federation of Greater Seattle and opened fire, killing one woman and injuring five others. This was reportedly carried out due to Haq's hatred for the nation of Israel. Haq's trial was conducted primarily over the course of 2008 and 2009 and it drew a very large amount of coverage. The articles covering the crime consistently invoked the term hate or bias crime in relation to his acts and subsequent charges. In addition to being found guilty of aggravated first degree murder for the one death, Haq was also found guilty on five counts of attempted first degree murder, and unlawful imprisonment. These charges were 
then topped with Haq being found guilty of violating Washington's malicious harassment law. ${ }^{132}$ Following the close of the Haq case, the number of local articles dropped considerably, but the overall number actually rose, as The Seattle Times ran 120 nationally focused articles with at least some reference to hate or bias crime in 2010 .

\begin{tabular}{|c|c|c|c|c|c|c|c|c|c|c|c|c|c|c|c|c|c|c|c|}
\hline \multirow[t]{2}{*}{ State } & & & & & & & & & & & & & & & & & & & \\
\hline & 1992 & 1993 & 1994 & 1995 & 1996 & 1997 & 1998 & 19992 & 2000 & 2001 & 20022 & 2003 & 2004 & 2005 & 2006 & 20072 & 20082 & 20092 & 2010 \\
\hline \multicolumn{20}{|c|}{ 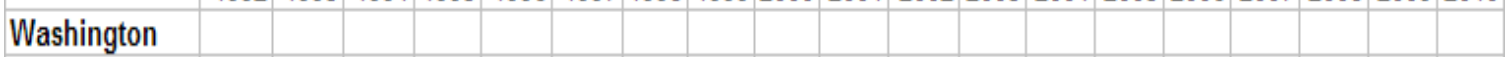 } \\
\hline Local Articles & 31 & 21 & 14 & 6 & 11 & 13 & 14 & 14 & 17 & 29 & 9 & 14 & 29 & 17 & 26 & 28 & 55 & 65 & 41 \\
\hline National Articles & 13 & 14 & 1 & 6 & 5 & 3 & 18 & 28 & 16 & 9 & 10 & 6 & 6 & 8 & 12 & 22 & 15 & 70 & 120 \\
\hline Total & 44 & 35 & 15 & 12 & 16 & 16 & 32 & 42 & 33 & 38 & 19 & 20 & 35 & 25 & 38 & 50 & 70 & 135 & 161 \\
\hline
\end{tabular}

Table 1- Local and National Articles in The Seattle Times: 1992-2010

The amount of reported FBI bias crime incidents in Washington State has shown some fluctuation between 1996 and 2009. The number has ranged from a high of 278 in 2001 to a low of 171 in 2005. On average there have been 209 bias crimes reported a year in Washington. On the whole, the numbers have been fairly level over the decade and a half covered by the FBI statistics, with the exception of a small rise between 1998 and 2001, followed by a subsequent small decline. There is no clear indication that the variance in the amount of articles over the years has a relationship to the total number of reported crimes. The number of articles did rise in the period between 1998 and 2001, but the majority of articles most of those years, with the exception of 2001 were focused on national stories related to bias crime. Perhaps most notably, the significant rise in the number of bias crime articles in The Seattle Times between 2006 and 2009 is not matched by a similar rise in FBI reported incidents. Also of note is the percentage of overall crime that bias crimes comprise. At no time in the fourteen years of data compiled by the FBI

\footnotetext{
${ }^{132}$ Sullivan, Jennifer \& Miletich, Steve. "Haq Convicted on All Counts in Jewish Federation Shootings." Seattle Times December 15, 2009.
} 
did the amount of bias crime account for even 0.001 percent of total crime. To put this more in perspective, on average between 1996 and 2009, one in every 1510 crimes $^{133}$ that were committed in the state of Washington were reported as a hate crime to the FBI. Therefore, it is likely that the fluctuation that did occur in incidents would be difficult to detect unless looking at the actual numbers. Ultimately, it does not appear as though the total number of bias crime articles is an indication of the amount of bias crimes being committed according to FBI statistics. As has been emphasized, high profile hate crimes (the post $9 / 11$ mosque attacks and the Haq case) seem to be a better predictor of greater media coverage in the case of the State of Washington and The Seattle Times. Although, even excluding these 'triggering' crimes coverage of bias or hate crime and related stories was the most prominent in this newspaper.

133 This includes violent and property crimes as compiled by the Federal Bureau of Investigation found at: http://www.fbi.gov/about-us/cjis/ucr/ucr. Accessed on April 6, 2011. 


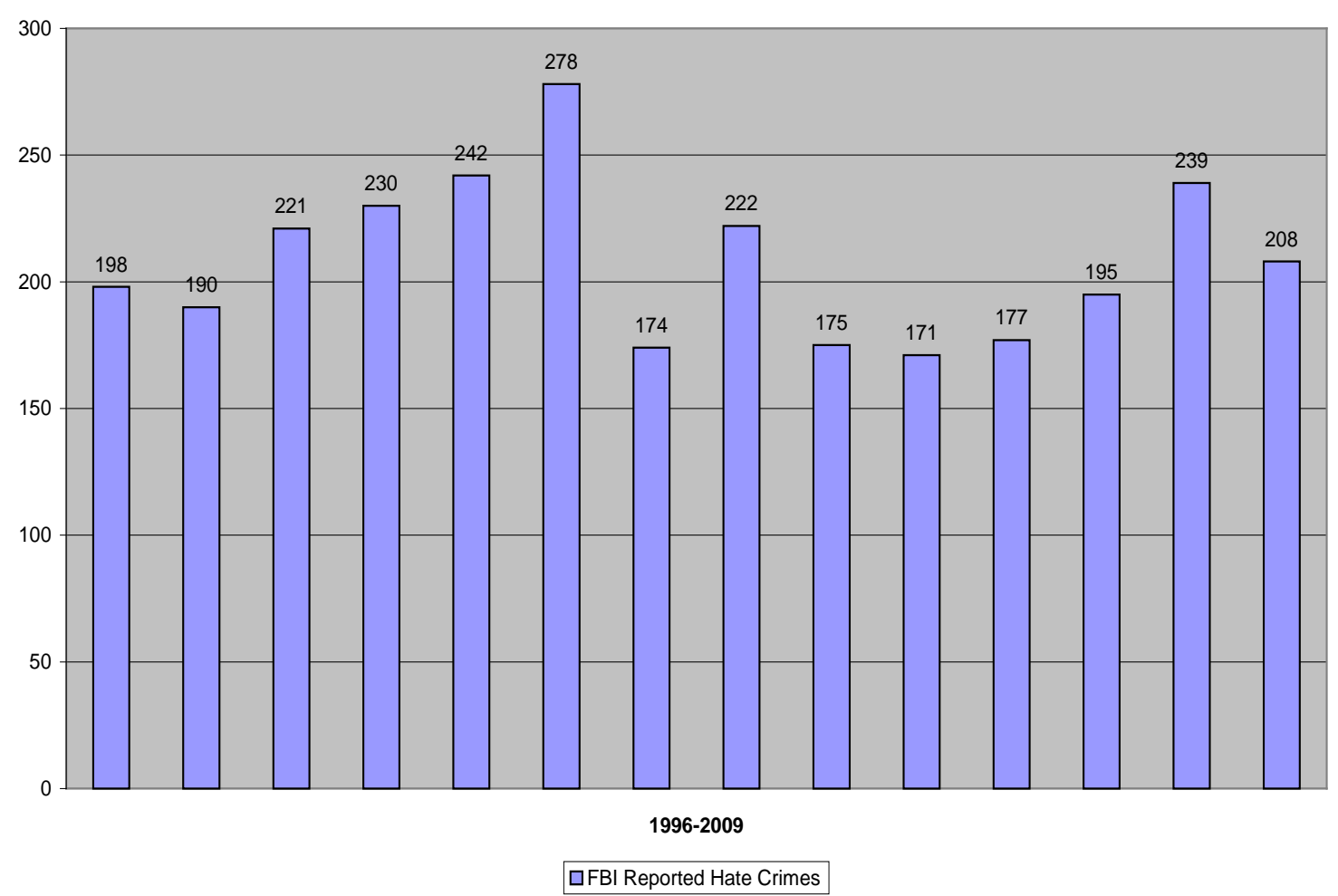

Figure 3- FBI Reported Hate Crimes in the State of Washington: 1996-2009

\section{Minnesota}

Data collected for the State of Minnesota runs from 1989 to 2010, which is the largest span of time covered in this content analysis. Out of the twenty-two years covered, 2008 and 2009 yielded the highest number of articles relating to hate or bias crime, both with a total of twenty-eight articles. The initial years of the 1990s saw a rise in bias crime related coverage in conjunction with newly passed legislation at the state level. Like the State of Washington this was then followed by a dip in coverage in the mid to late nineties, reaching a low of three articles in 1995. The amount of coverage in Minneapolis Star-Tribune increased in 1998 and has remained fairly steady at totals in 
the teens with the exception of the aforementioned increase in 2008 and 2009. The basic pattern of coverage in Minneapolis Star-Tribune resembles that of Washington and The Seattle Times with increased coverage around the passage of legislation, a subsequent drop of in the in the amount of articles followed by an increase in the late 90 s and early 2000s which held fairly consistent until an rise in recent years. Although, the recent increases in the total amount of articles in Minneapolis Star-Tribune are not nearly as dramatic as those seen in The Seattle Times.

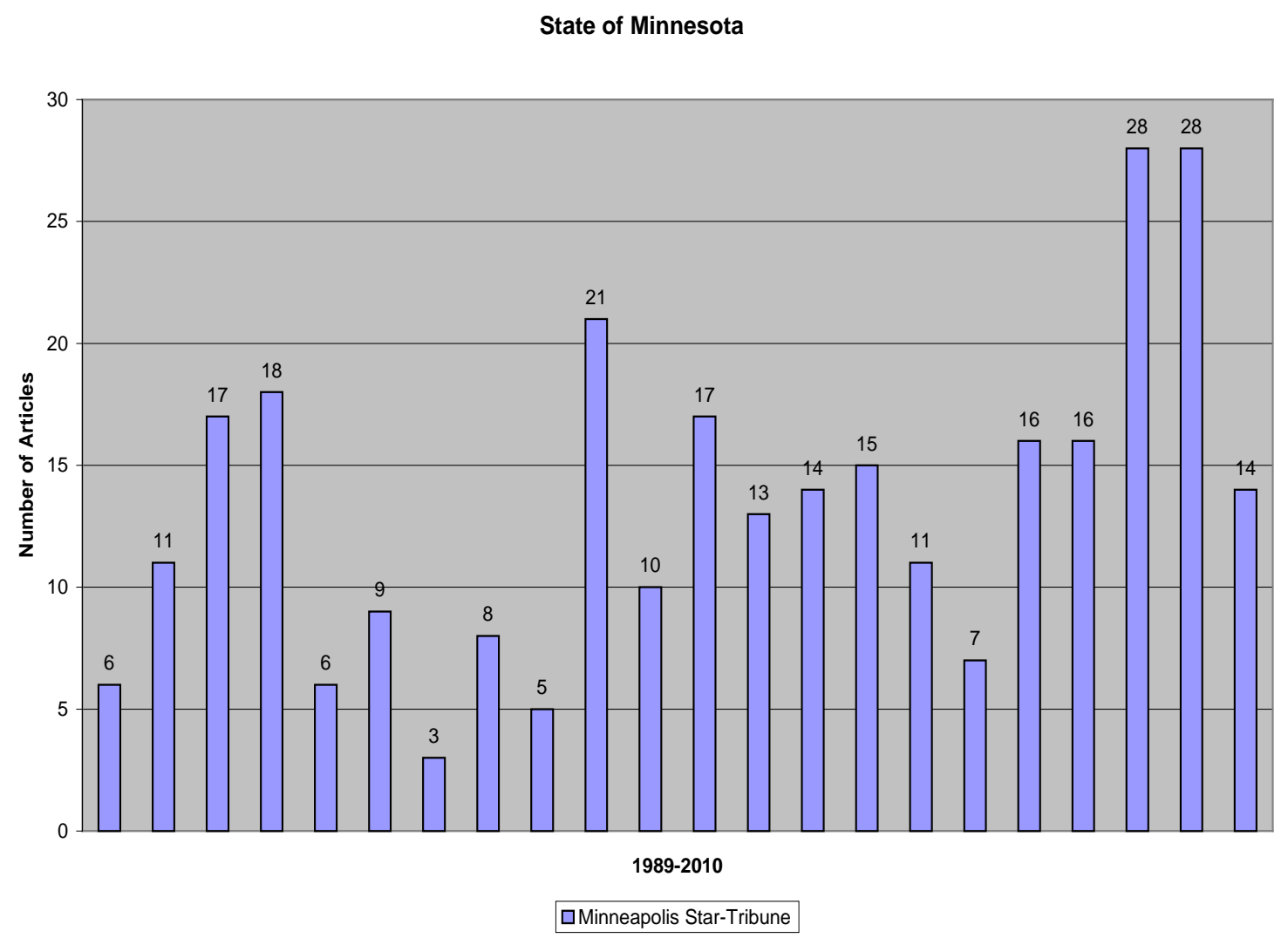

Figure 4- Bias Crime Related Articles in Minneapolis Star-Tribune: 1989-2010

For the most part, the articles produce by Minneapolis Star-Tribune have been local in nature over the last twenty-two years, but the share of articles that fall under the out of state or national categorization has grown in the last three years. Prior to these 
recent years the largest amount of national level articles was in 1998, again primarily due to coverage of the high profile out of state hate crimes targeting James Byrd and Matthew Shepard. The recent increase has largely been largely the result of coverage focusing on the previously mentioned recent push of the federal hate crime act named after Byrd and Shepard and its subsequent passage. This is true particularly as it relates to 2009 when the amount of national articles matching the number of local articles produced by Minneapolis Star-Tribune. There was no local crime of a particularly sensational character in all the years covered of Minnesota that rivaled that of the Haq case in Washington. So the majority of local articles detailed relatively minor bias crime offences, as well as the describing and listing of events aimed at encouraging awareness and discussion of hate crime.

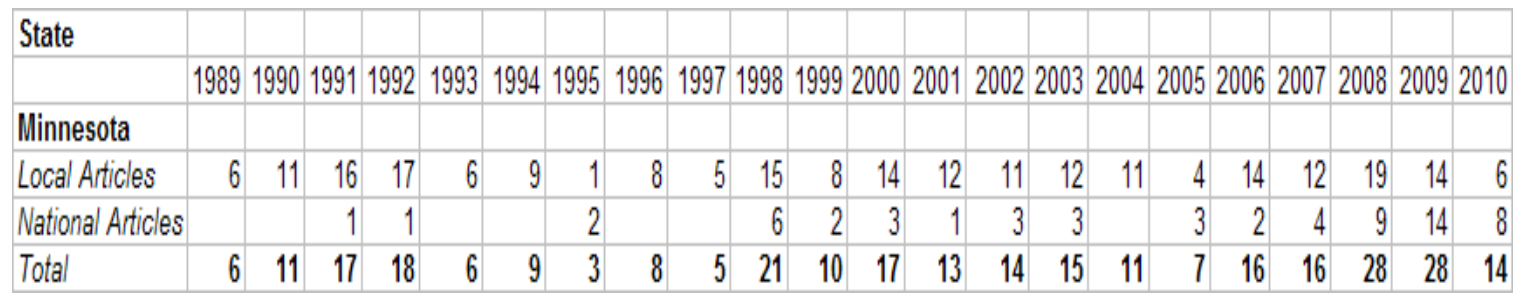

Table 2- Local and National Articles in Minneapolis Star-Tribune: 1989-2010

The reported incidents of hate or bias crime in Minnesota in the span of 1996 to 2009 have ranged from a high of 268 in 1996 to a low of 137 in 2006, showing a larger amount of fluctuation than Washington. The average over this span of fourteen years is 201, which is not far from the number in Washington. However, the amount of reported bias crimes accounted for a consistently lower amount on average over the last four years of FBI compiled statistics, landing at an average of about 150 incidents per year. Minnesota is the only state in this analysis that has an amount of hate crime that reaches 
0.001 percent of total crime, which was the case in eleven of the fourteen years. This translates to an average of one in every 908 crimes being categorized as a bias crime. While this total is notable in a statistical sense when compared to the other three states, it seemingly would make little difference in public perception of bias crime frequency since the amount of bias crime relative to the overall total is still very small, even if bias crime accounts for a noticeably greater amount than it does in the three other states.

Additionally, due to their trending in opposite directions, it does not appear as though the number of bias crimes in Minnesota aligns in any significant way with the total number of articles in Minneapolis Star-Tribune.

State of Minnesota

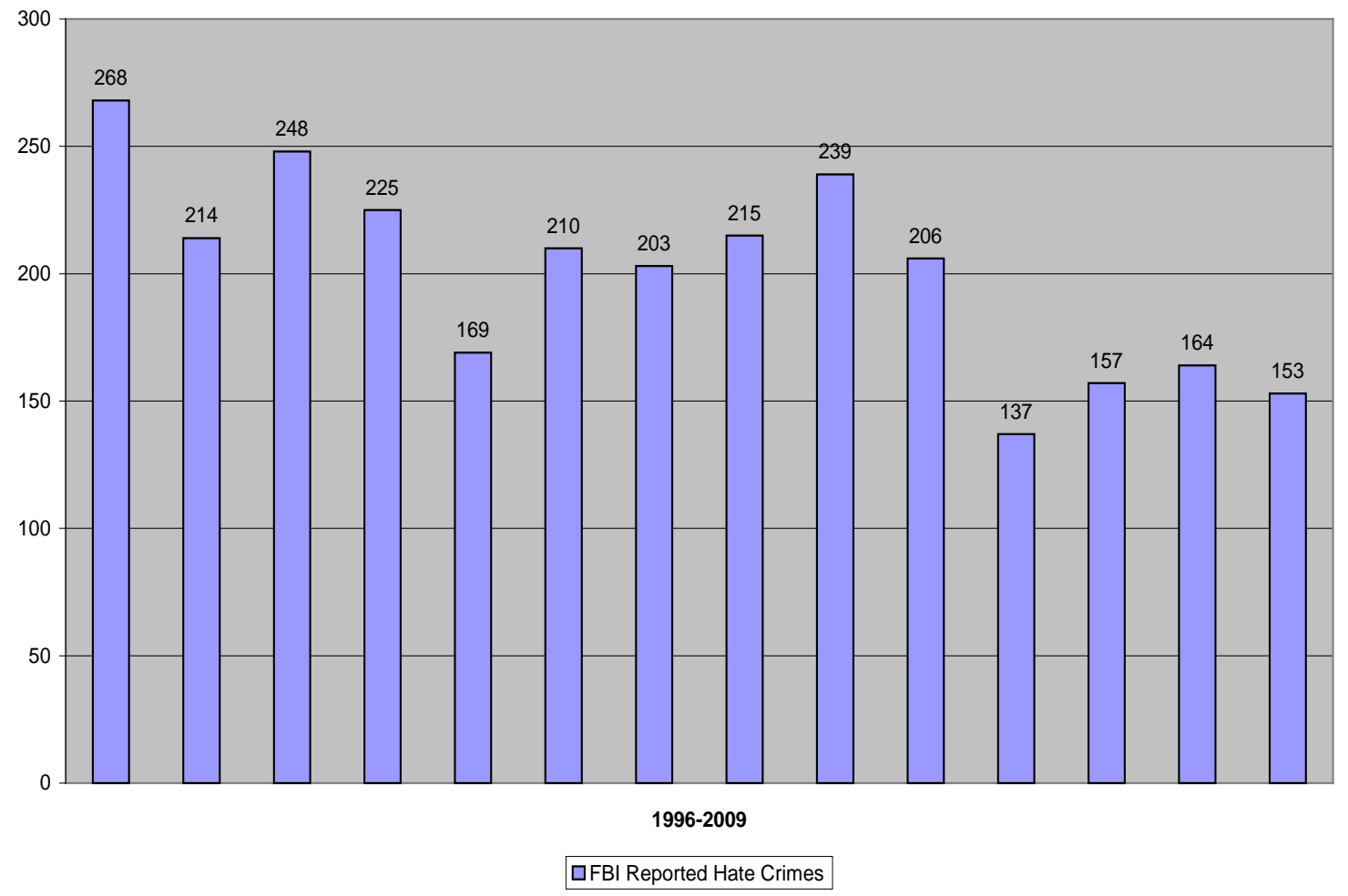

Figure 5- FBI Reported Hate Crimes in the State of Minnesota: 1996-2009 
Perhaps the most notable aspect of the numbers compiled for Minnesota is that despite the shifts in the overall number of articles in Minneapolis Star-Tribune aligning to a certain extent with those found in The Seattle Times, the amount of articles was consistently lower. At the same time during much of the period covered by both the Washington and Minnesota content analysis the amount of reported hate crimes was comparable. This presents a bit of a surprise, even if the coverage in Minnesota is greater than the other two states in this analysis questions still arise as to why the amount of attention paid to bias crime related stories is far less in Minneapolis Star-Tribune than The Seattle Times.

\section{South Carolina}

The most limited amount of coverage of bias crime and issues surrounding bias crime was represented by The Charleston Post and Courier, South Carolina's largest newspaper. The amount of articles written in a given year, between 1995 and 2010, never rose above that of 14 in 1996 . The peak period, so to speak, of bias crime related articles ran from 1996 to 1999. These are the years when the possibility of a bias crime statute passing in the state legislature looked most likely. At first it appeared as though a uniquely local character was evident in the articles during this period of time in that only one out of forty was focused on a national or out of state bias crime story. However, the amount of coverage of national stories remained low throughout the time covered in this analysis and accounted for only three in all sixteen years. It appears that the Post and 
Courier did not feel inclined to seek articles about hate crime from the national scene whether or not there were relevant local stories.

\begin{tabular}{|l|r|r|r|r|r|r|r|r|r|r|r|r|r|r|r|r|}
\hline State & 1995 & 1996 & 1997 & 1998 & 1999 & 2000 & 2001 & 2002 & 2003 & 2004 & 2005 & 2006 & 2007 & 2008 & 2009 & 2010 \\
\hline South Carolina & & & & & & & & & & & & & & & & \\
\hline Local Articles & 7 & 13 & $\mathbf{8}$ & 9 & 9 & 4 & 5 & 4 & 3 & 1 & 1 & & 7 & 10 & 6 & 6 \\
\hline National Articles & & 1 & & & & & 1 & & 1 & & & & \\
\hline Total & $\mathbf{7}$ & $\mathbf{1 4}$ & $\mathbf{8}$ & $\mathbf{9}$ & $\mathbf{9}$ & $\mathbf{4}$ & $\mathbf{6}$ & $\mathbf{4}$ & $\mathbf{4}$ & $\mathbf{1}$ & $\mathbf{1}$ & $\mathbf{0}$ & $\mathbf{7}$ & $\mathbf{1 0}$ & $\mathbf{6}$ & $\mathbf{6}$ \\
\hline
\end{tabular}

Table 3- Local and National Articles in The Charleston Post and Courier: 1995-2010

The overall lack of bias crime articles hit a low of none in 2006, which was preceded by only one for both 2004 and 2005 . These numbers picked up in the latter part of the decade, returning to numbers close to those seen during the debate over bias crime legislation at the state level. These more recent articles focus almost exclusively on local incidents or crimes, since the debate regarding possible legislation at the state level has effectively been brushed aside for approximately a decade. The reference to bias crime found in these articles is generally in the quotes of victims or groups who are labeling an incident as a hate crime and expressing an unfavorable view of South Carolina having no bias crime legislation, which is then confirmed by the author. ${ }^{134}$ This kind of articles provides an example of what would logically lead to a state with no bias crime laws have a smaller level of media coverage referencing bias crime. Since the state does not prosecute bias crimes as such it becomes likely that they will be reported as simply assaults or vandalism unless a victim, or an advocate for a victim, attempts to label a crime as being bias motivated. When a basic report of an incident simply addresses the arrest and prosecution of a crime in a state with no hate crime laws, it is far less likely to

\footnotetext{
${ }^{134}$ Parker, Adam. "Mom Urges Hate Crime Law in S.C.” Charleston Post and Courier May, $27,2007$. Parker, Adam. "Three Cleared in Cross Burning." Charleston Post and Courier October 18, 2008.
} 
be labeled a hate crime. This can perhaps be best illustrated by comparing the amount of articles in the Post and Courier with the number of hate crimes in South Carolina according to the FBI.

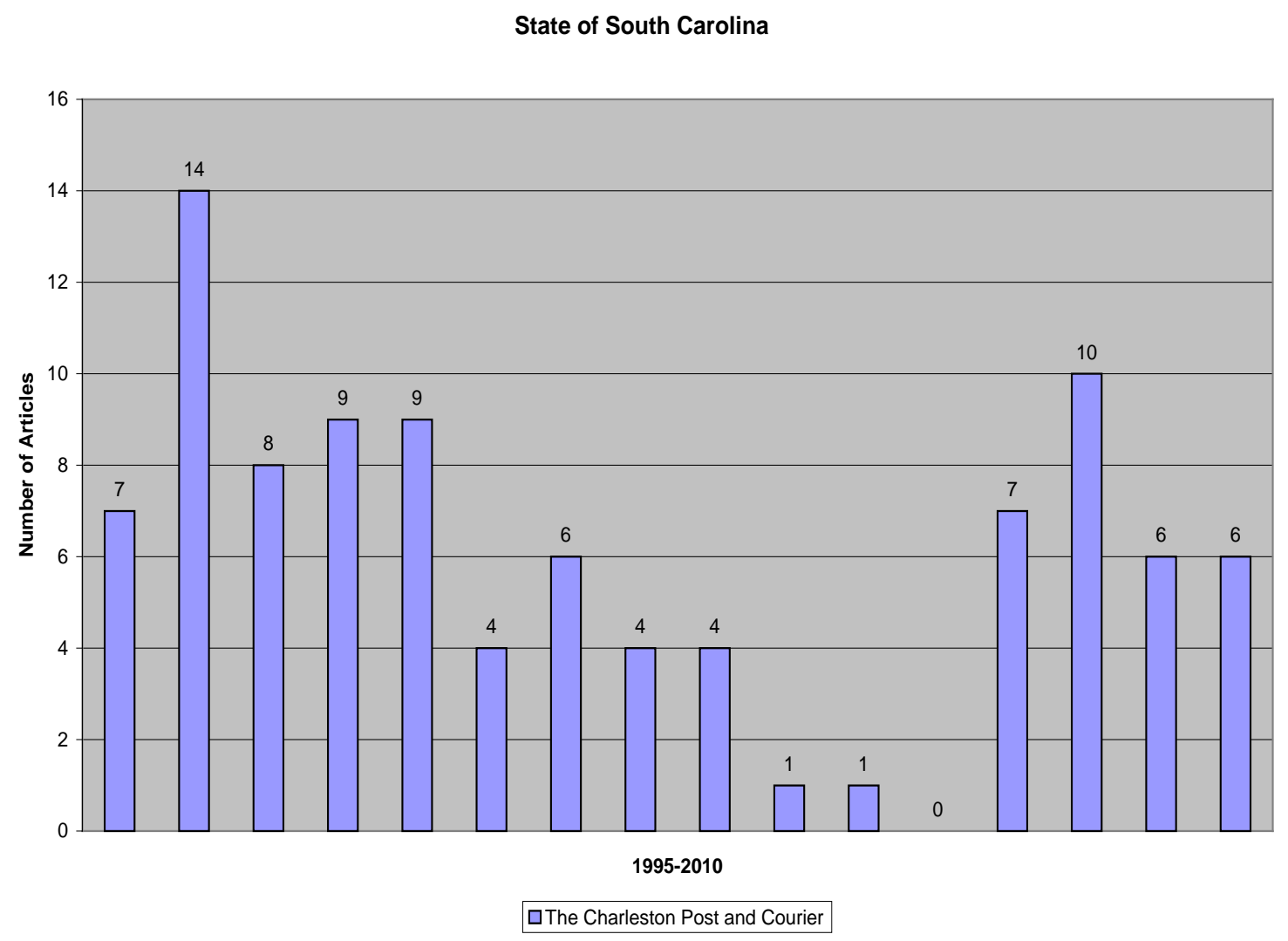

Figure 6- Bias Crime Related Articles in The Charleston Post and Courier: 1995-2010

The range in reported hate crime incidents spans from 33 in 2000 to 153 in 2008.

The majority of the lower totals occurred between 1996 and 2003, when the average amount of reported hate crimes was 57. From 2004 to 2009, that number proceeded to jump to an average of about 120, or over double the amount of the previous eight years. 2004 is the same year that the number of bias crime related articles in the Post and Courier dropped to one, was followed by one in 2005, and dropped to none in 2006 . During the first few years of a fairly steep rise in reported bias crime incidents, bias crime 
related articles were virtually nonexistent. The total number of articles picked up slightly between 2007 and 2010 but were still nowhere near as numerous as the amount of bias crimes articles in Minnesota, and especially Washington. The total of bias or hate crimes in South Carolina were reaching a level comparable to Minnesota's, and far closer to Washington's than it had been in the past, but there were few articles detailing bias crime incidents or issues. For example, in 2009 there was one local article for every 21 bias crimes in The Charleston Post and Courier, in Minneapolis Star-Tribune there was one local article for every 11 crimes, and in The Seattle Times there was one local article for every 3 crimes. Such an outcome is understandable when bias crimes are not charged with that label and thus are far less likely to be reported on by the media as bias or hate crimes. Seemingly, this would also imply that there is less public awareness. 


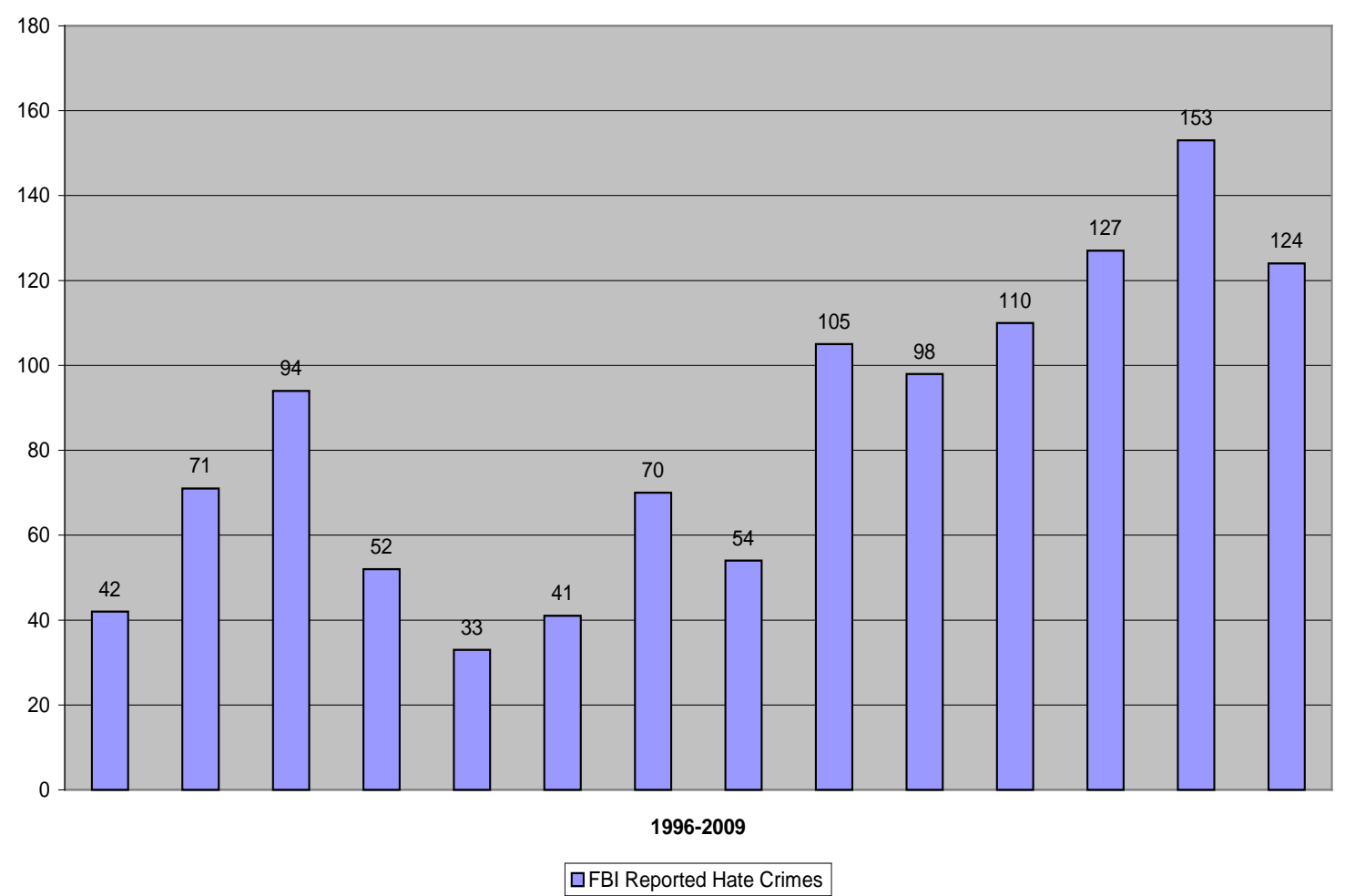

Figure 7- FBI Reported Hate Crimes in the State of South Carolina: 1996-2009

It should be acknowledged that the reporting of hate crime incidents in states that have not passed data collection legislation can be less accurate than the data coming from those states that have such a statute. ${ }^{135}$ As was previously mentioned, there is research that points to underreporting of hate crime in states like South Carolina who have a history of racial turbulence. ${ }^{136}$ Due to this, even if South Carolina's number cannot be taken entirely for granted, it should not negate the previous point regarding the incredibly disproportionate amount of articles when compared to the amount of reported bias motivated crimes in South Carolina, and how the underreporting is perhaps to be

\footnotetext{
${ }^{135}$ Levin and McDevitt (2002).

${ }^{136}$ King, R. D., Messner, S. F., \& Baller, R. D. (2009).
} 
expected when no charges can be filed. As both Washington and Minnesota show, overall numbers rising or dropping do not predict a comparable rise or drop in articles, but it is still of note that the number of articles in the Post and Courier is decidedly lower than that of the other two states' largest papers when the amount of crime they encountered was similar in the latter part of the last decade.

\section{Wyoming}

Most of the time period covered in the content analysis of articles in The Wyoming Tribune-Eagle finds that this paper had similar coverage of bias crime to that of The Charleston Post and Courier, the major exception to this being the years 1998 and 1999. These two years saw The Wyoming Tribune-Eagle print 32 and 50 articles respectively that mentioned hate or bias crime. The rest of the time covered saw an average of 4.4 articles a year, a number much more in line with that found in South Carolina. For example, in both 2004 and 2005 there was just one article to be counted each year. 


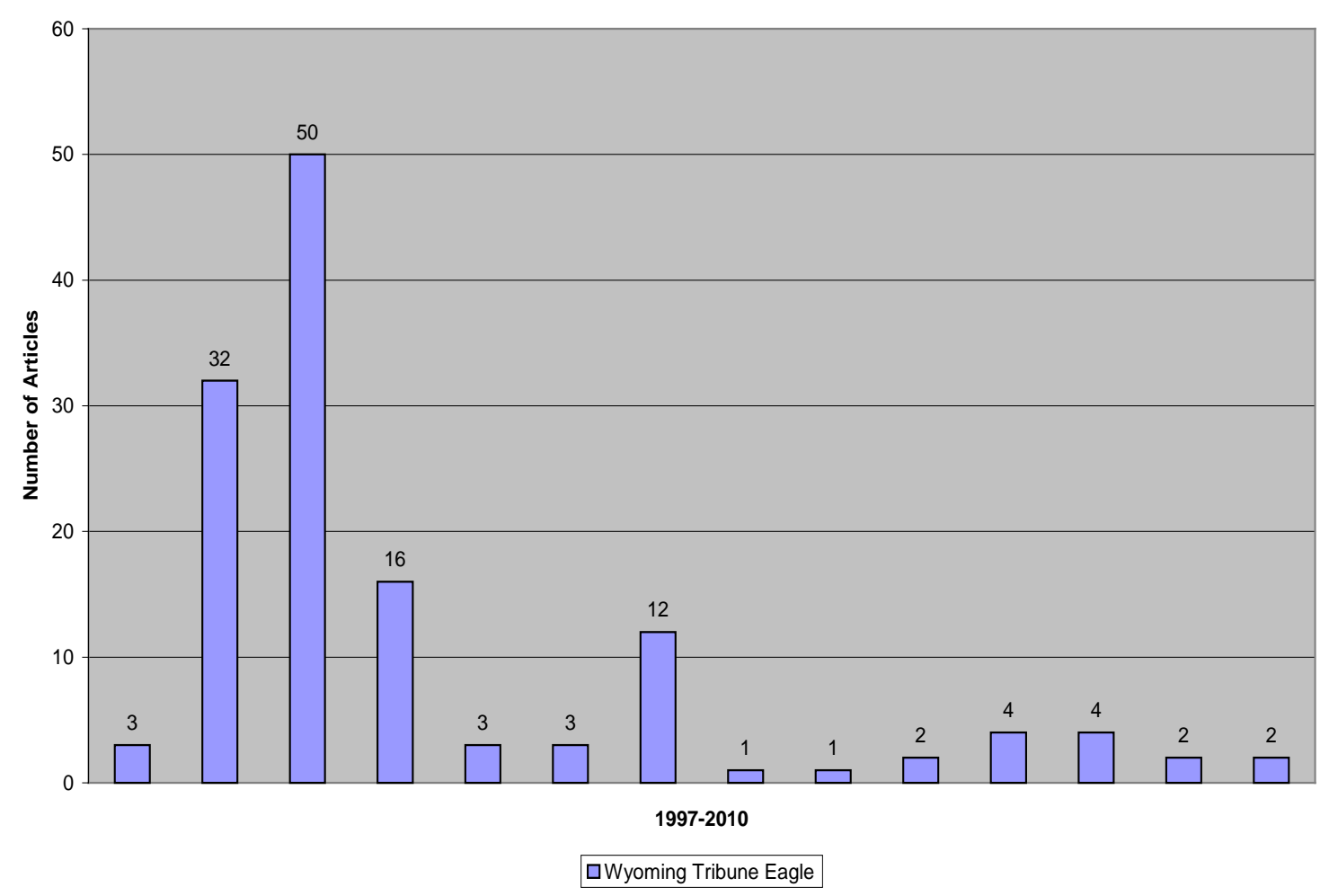

Figure 8- Bias Crime Related Articles in The Wyoming Tribune-Eagle: 1997-2010

Why there was a spike seen in 1998 and 1999 can in some part be owed to a common factor found in all four states. Over these two years, and particularly in 1999, bias crime legislation was introduced and considered by the state legislature. However, adding to the number of articles around this time was one of the largest 'triggering' hate crimes to take place in the entire United States over the last twenty years. The widely covered murder of Matthew Shepard is what prompted this push for hate crime legislation in 1998 and 1999. The prominence of the Shepard murder ensured that coverage of bias or hate crime issues would be considerably high, and would far exceed the jump seen in The Charleston Post and Courier when the State of South Carolina was considering bias crime legislation. Still, the Wyoming legislature rejected bias crime 
legislation in 1999 and its lack of consideration since ${ }^{137}$ perhaps ensured low numbers in subsequent years in The Wyoming Tribune-Eagle, numbers that were on par with those found in South Carolina. Notably, there was an increase in 2003 owed largely to that year marking the fifth anniversary of Shepard's death, a subject that accounted for half the articles. Notably, the overall percentage of articles in The Wyoming Tribune-Eagle referencing Matthew Shepard between 1997 and 2010 was actually slightly higher than this landing at 53 percent.

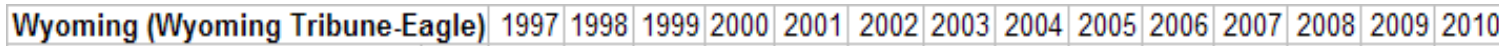
Local Articles National Articles Total

\begin{tabular}{|l|r|r|r|r|r|r|r|r|r|r|r|r|}
3 & 30 & 46 & 15 & 3 & 3 & 12 & 1 & 1 & 2 & 3 & 1 & 2 \\
\hline
\end{tabular}

\begin{tabular}{|l|r|r|r|r|r|r|r|r|r|r|r|r|r|r|r|r|r|}
\hline & & 3 & 32 & 50 & 16 & 3 & 3 & 12 & $\mathbf{1}$ & $\mathbf{1}$ & $\mathbf{2}$ & $\mathbf{4}$ & $\mathbf{4}$ & $\mathbf{2}$ & 2 \\
\hline Matthew Shepard Articles & & & & & & & & & & & & \\
\hline Percentage of Total & 71 & 25 & 27 & 6 & 1 & 1 & 6 & 1 & & & 2 & 2 \\
\hline
\end{tabular}

Table 4-Local and National Articles in The Wyoming Tribune-Eagle: 1997-2010

The data collected from Casper Star-Tribune is of a markedly different character than much of what was found in The Wyoming Tribune-Eagle and certainly the data from The Charleston Post and Courier. Again, in large part this can be attributed to Wyoming being the setting for the murder of Matthew Shepard. Even though data was compiled starting in 2003 , nearly five years after Shepard's death, a great deal of the coverage relating to bias crimes was focused on that particular hate crime and its fallout. Between 2003 and 2010 there were well over 100 articles in Casper Star-Tribune focused on the Matthew Shepard case, though not all of these were used in this content analysis due to many making no direct mention of bias or hate crime.

\footnotetext{
${ }^{137}$ Lowell, Jessica. "Bias-Crime Bill Dropped Before Session Begins." The Wyoming Tribune-Eagle February, 16 2000. Sec. A1.
} 


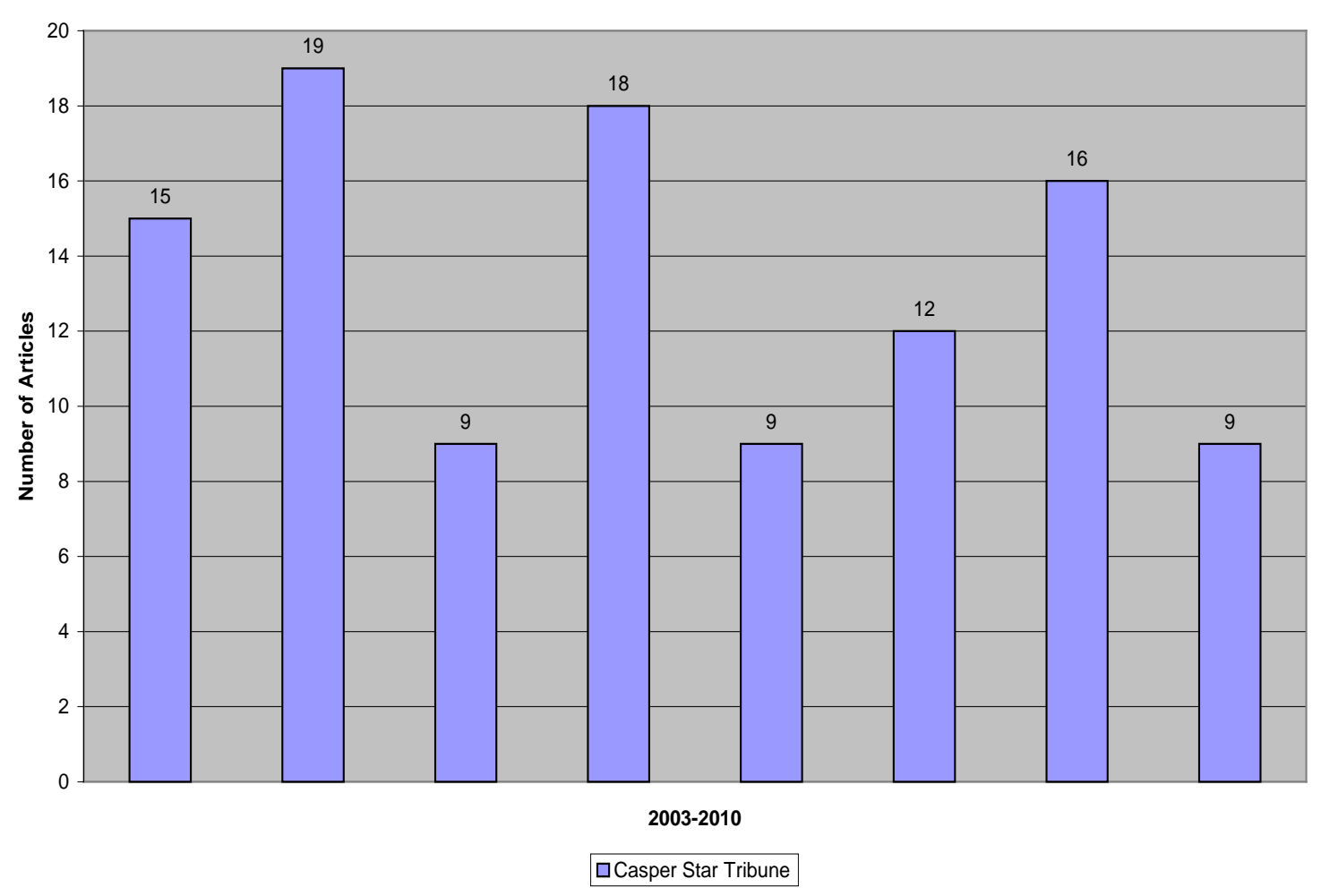

Figure 9- Bias Crime Related Articles in Casper Star-Tribune: 2003-2010

Between 2003 and 2010 the number of bias crime related articles in Casper StarTribune was far less than the amount run by The Seattle Times, and it did not quite reach the same number of overall articles run by Minneapolis Star-Tribune. However, it was generally far more engaged with the issue of hate or bias crime than The Wyoming Tribune-Eagle and South Carolina's The Charleston Post and Courier, publishing 106 articles to the Tribune-Eagle's 28 and the Post and Courier's 35 in the years spanning 2003 to 2010. The number of articles fluctuated slightly for Wyoming's biggest paper. The total peaked at eighteen in 2006, never dropped below nine in a given year, and the split between locally focused and nationally or out of state centered articles was fairly balanced overall, at 64 and 42 respectively. While the amount of space dedicated to 
Matthew Shepard related articles remained high throughout the time period examined, it reached its height in the years between 2007 and 2009. This was due to coverage of the first attempt by Congress to pass the Matthew Shepard Hate Crime Prevention Act in 2007 , followed by the tenth anniversary of his death in 2008 , and subsequently the passage of the Matthew Shepard and James Byrd Jr. Hate Crime Prevention Act in 2009. ${ }^{138}$

\begin{tabular}{|l|r|r|r|r|r|r|r|r|r|}
\hline Wyoming (Casper Star-Tribune) & 2003 & 2004 & 2005 & 2006 & 2007 & 2008 & 2009 & 2010 \\
\hline Local Articles & 12 & 12 & 5 & 7 & 2 & 10 & 9 & 8 \\
\hline National Articles & & 3 & 7 & 4 & 11 & 7 & 2 & 7 & 1 \\
\hline Total & & $\mathbf{1 5}$ & $\mathbf{1 9}$ & $\mathbf{9}$ & $\mathbf{1 8}$ & $\mathbf{9}$ & $\mathbf{1 2}$ & $\mathbf{1 6}$ & $\mathbf{9}$ \\
\hline & & & & & & & & & \\
\hline Matthew Shepard Articles & 53 & 5 & 13 & 2 & 4 & 5 & 10 & 11 & 3 \\
\hline Percentage of Total & $\mathbf{5 0 \%}$ & & & & & & & & \\
\hline
\end{tabular}

Table 5- Local and National Articles in Casper Star-Tribune: 2003-2010

Perhaps the most surprising aspect of the coverage seen in Casper Star-Tribune is how it relates to the actual amount of bias crime incidents shown in FBI statistics. Naturally, the rate of bias or hate crime would be expected to be lower in a low population state, as the number of total crime would be. Indeed, the total number of bias crime incidents in Wyoming is decidedly smaller than the three other states. Between 1996 and 2009 it has never been reported as higher than 21 in 2007 and has been as low as 2 in 1999. The average over this span of time has been 7 incidents a year. Such a low number of incidents makes the relative amount of coverage stand out, and adds further evidence to the notion that the overall amount of bias crime in a state does not accurately

\footnotetext{
138 "Wyoming Senators Oppose Hate Crimes Measure." Re-print from Associated Press September 28, 2007.

Gray, Kristy. "Tenth Anniversary of Shepard Murder Puts Focus Back on Wyoming, Laramie.” Casper Star-Tribune October 11, 2008.

Pelzer, Jeremy. "Civil Rights Leaders Praise Matthew Shepard Hate Crime Prevention Act." Casper Star-Tribune October 28, 2009.
} 
predict media coverage. For example, in 1999 The Wyoming Tribune-Eagle ran one article for every 0.04 bias crimes. Further, if using 2009 to calculate a ratio of articles to crimes, as was done previously with the three other states, Casper Star-Tribune ran one local bias crime related article for every 0.8 bias crime incidents in the state. Needless to say, the analysis of Wyoming's largest newspaper painted a much different picture of the media's approach to bias or hate crime in that state than was expected. ${ }^{139}$

\section{State of Wyoming}

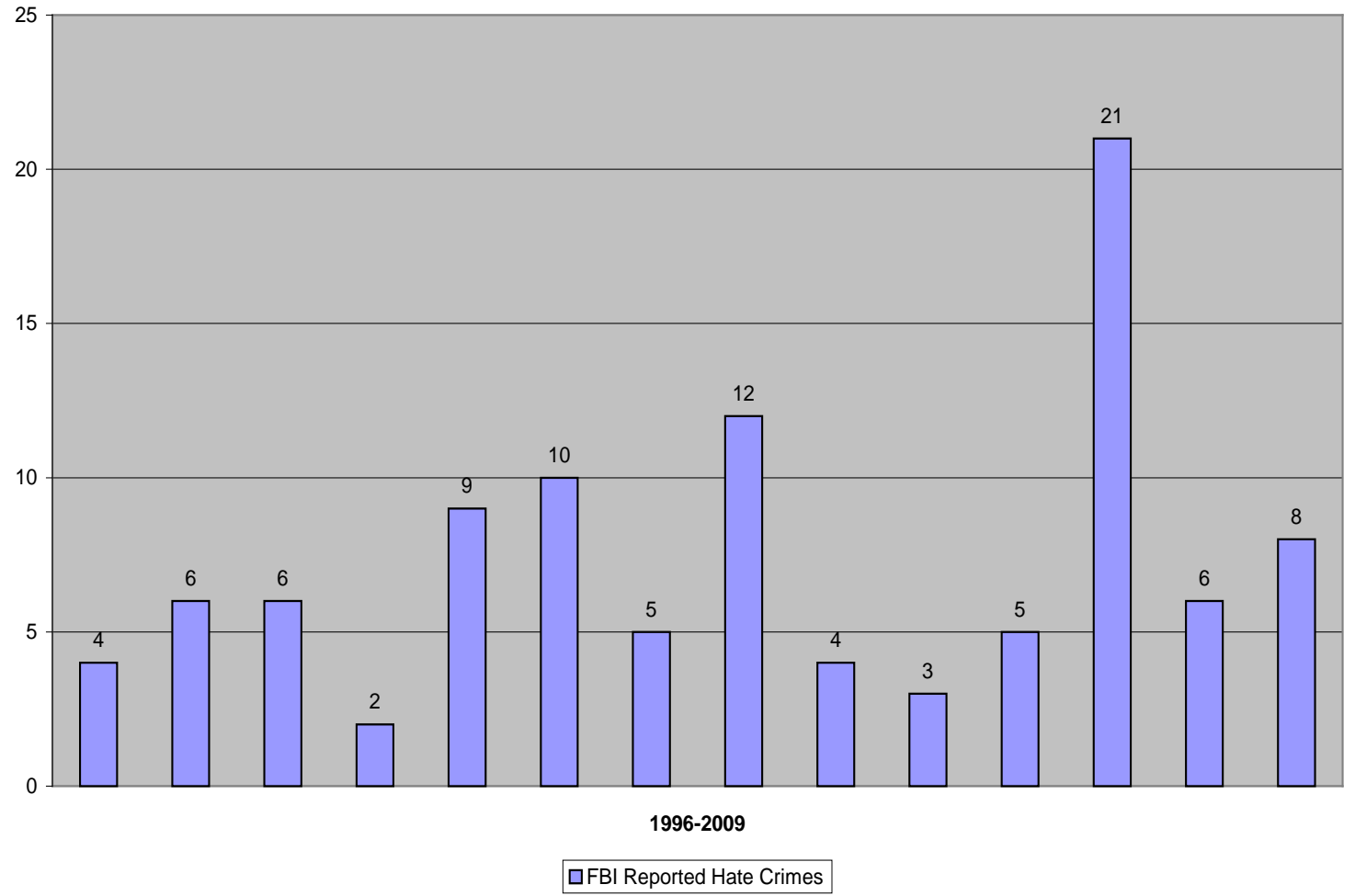

Figure 10- FBI Reported Hate Crime in the State of Wyoming: 1996-2009

\footnotetext{
139 The same caution should be taken when observing the FBI statistics for Wyoming incidents as was suggested regarding South Carolina's numbers. However, it should be kept in mind that historical racial turbulence does not bare the same relevance to Wyoming. Therefore, while many in Wyoming may be resistant to bias legislation they are less perhaps less likely to avoid the acknowledgment of crimes aimed at minorities because of that status.
} 


\section{Chapter 7:}

\section{Discussion and Conclusion}

The results of this content analysis in many ways align with the assumptions put forth prior to it being conducted. The overall amount of articles was higher and more consistent in both Washington and Minnesota, the two states that have passed extensive bias crime legislation. Additionally, the amount of articles printed in The Seattle Times and Minneapolis Star-Tribune has increased over time and seems to be holding at higher numbers in the last decade. Despite common trends there is a noticeable difference in the amount of articles found in Washington and Minnesota. This is particularly of note due to the comparable character of their bias crime laws and a similar total of reported hate crimes occurring in each state. Due to such similarities, one might expect the total number of articles in each state's largest newspaper to come much closer to matching. However, one reasonable explanation for such a difference is perhaps found in a greater amount of high profile hate crime cases occurring in the State of Washington. For example, a good deal of the increase in articles published by The Seattle Times in the last half decade can be owed to the aforementioned Haq case. The importance of high profile or 'triggering' bias crimes in predicting media attention does not completely explain the differences between Washington and Minnesota, but does provide some explanation, and also helps illuminate the surprising results found in Wyoming.

South Carolina also fell largely in line with some basic assumptions due to The Charleston Post and Courier not running many bias crime related articles between 1995 and 2010. Wyoming, however, provided some unexpected results. The amount of 
coverage was much higher than expected before the content analysis was conducted. Again, a notable feature of the coverage in both Wyoming newspapers was the amount related to the murder of Matthew Shepard, in both local and national articles. The total number of articles in The Wyoming Eagle-Tribune that make mention of Shepard account for 53 percent of stories, and in Casper Star-Tribune such articles account for 50 percent of the overall total. Seemingly, the death of Shepard, its fallout, and the national attention it received, which culminated in the passage of federal legislation bearing his name, could have trumped the factors that would have led to results more in line with those displayed in South Carolina. Still, while the largest paper, Casper Star-Tribune, has continued to provide a fair amount of bias crime articles over the last decade, The Wyoming Tribune-Eagle's coverage fell of to a level basically on par with The Charleston Post and Courier despite a burst of Matthew Shepard related stories at the close of the 1990s.

The surprising numbers seen in Wyoming also point to the seeming lack of predictive power to be found when comparing the reported bias crime incidents compiled by the Federal Bureau of Investigation and the amount of coverage bias crimes receive. In a very basic sense there appears to be no distinct correlation between a rise, or fall, in the number of articles printed by any of the four papers and a rise or fall in reported incidents reported by the FBI. Of course, even if there were a seeming correlation between these two elements, any real conclusions regarding their relationship would require a thorough statistical analysis controlling for factors not touched on in this piece. 
That being said, the amount of coverage devoted to bias crime issues in a given state appears to be a function more of a general approach to reporting on bias crime or the presence of a particularly high profile hate crime, rather than it being a function of overall bias crime numbers. For example, The Seattle Times saw a jump in coverage in the past half decade seemingly due to simply finding such stories relevant, and more specifically the high profile crime committed by Naveed Haq and the move toward passage of federal legislation. The overall number of crimes in Washington did not significantly increase over this period of time. Also, as reported incidents increased over the past two decades in South Carolina, The Charleston Post and Courier actually went through a period of reporting virtually none and then for a year literally not one article. Finally, coverage in The Wyoming Tribune-Eagle and Casper Star-Tribune was driven largely by one case in particular, and far outweighed the amount of reported bias crime incidents.

Most relevant to the initial questions posed by this project, The Seattle Times and Minneapolis Star-Tribune provide some evidence that in a state with extensive bias crime law, the coverage highlighting bias crime is more consistent and increases over time. In Washington State, high profile crimes may have occurred, but did not account for nearly as much of the media coverage of bias crime as one crime did in Wyoming. While not conclusively providing evidence that these are phenomena resulting from the passage of bias crime legislation, it does on the surface appear as though the some of the desired expressive effects put forth by advocates have occurred in Washington and Minnesota regardless. 
On the other hand, The Charleston Post and Courier in South Carolina has largely avoided covering bias crime related stories. As was previously mentioned, this could have much to do with the lack of bias crimes being labeled bias crimes because they cannot and will not be prosecuted as such. This outcome is occurring despite the FBI reported amount of bias crimes not being far from the two states that consistently displayed the most media coverage. The lack of bias crime laws in South Carolina appears to limit the amount of attention paid by the media to acts motivated by the hatred of individuals or groups based on their descriptive characteristics. Therefore it does not seem unreasonable to assume that a similar perspective or lack of attention is paid by the public in general, which would describe the kind of societal view of passivity or indifference relating to hate crimes that bias crime legislation advocates seek to remedy.

Still, the differences in the attention paid by the largest papers in the State of Washington and the State of Minnesota especially in recent years provides evidence that a comparable passage of bias crime laws does not guarantee the same amount of media coverage. This along with the unexpectedly large amount of coverage in Wyoming in the last decade and a half points to the conclusion that the expressive goals of bias crime legislation, when assessed through the media, are certainly not solely predicted through the passage of legislation.

\section{Conclusion}

Since states first began to address 'hate crime' in the 1980 s by passing legislation directly aimed at this previously existing yet not widely labeled form of crime, the 
eradication of bias motivated incidents was by no means the sole objective of the laws. Instead advocates for the implementation of hate crime laws saw the need to send a message to communities, both those victimized by such crimes and the community at large, as equally important. Confronting ideological motivations behind a plethora of different forms of crime was seen as vital to assuring various long targeted and frequently marginalized populations that the government and their communities found these ideologies unacceptable. Bias crime laws are meant to express to these populations and individual victims that the justice system is properly addressing such crimes even if they exist. Beyond the general wish for an even more cohesive and genuinely equitable society following the successes of various rights movements in the $1960 \mathrm{~s}$ and $70 \mathrm{~s}$, messaging of this nature can help avoid retaliatory actions and vigilantism on the part of an initially victimized group or individual.

The importance of the messaging or 'expressive' goals and outcomes related to bias crime legislation has perhaps been thrown into greater relief as the number of FBI categorized hate crimes has held fairly steady since statistics were first collected in the 1990s. It is difficult to point to any clear instrumental success with the passage of bias crime legislation at the national or state level. Thus, it appears as though there might always be a small amount of bias crime behind which lies ideologies that will entail the targeting of victims based on their descriptive characteristics.

As this piece touched on earlier, advocates for hate crime laws have been, by and large, more successful than their opponents. It does not appear as though this form of law will be reversed or removed to any great extent in the coming years. Still, as with any 
form of policy, it is of value to be able to clearly assess if bias crime legislation is having the effect it was put in place to realize. Since the instrumental effects of bias crime laws are difficult to find or appear neutral, how then do we measure how successful the more expressive goals of bias crime legislation have been?

This project attempted to at least find an avenue for such measurement by looking at variations in how frequently some of the largest local level newspapers in four different states reported on bias or hate crime related issues; the theory being that if bias crime legislation advocates want a community to pay attention, be concerned, and ultimately condemn hate crimes in support of victimized groups, local media would need to highlight bias crime and the issues that surround it. Therefore, the success of government messaging inherent in bias crime laws should be reflected, and perhaps measurable, within local media.

Some results were as expected. Media coverage was generally greater in the states (Washington and Minnesota) with extensive bias crime legislation, and lower in those with virtually none (South Carolina and Wyoming). It also increased over time in the two states with more hate crime laws after those laws had been passed. In South Carolina and Wyoming there was a burst of reporting when their respective state legislatures were toying with the notion of passing bias crime legislation, but coverage faded greatly in South Carolina in the years after the issue was dropped. This was not so much the case in Wyoming. Yet, those surprising totals where greatly skewed when the most high profile United States hate crime of the last two decades took place within that state. 
This project perhaps only scratches the surface of what could be found by taking a similar approach on a much larger scale. For example, one might collect data for the entirety, or a least a larger sampling, of each state's print media. This would likely help in creating a more detailed picture of how each state has reacted to bias crime legislation. It would also perhaps be of value to collect a larger and even more varied sampling of states, and see what effect the different gradations of laws passed amongst these states might have had on variations in how bias crime is covered by their media. While this piece addresses factors beyond simply the passage of bias crime legislation that might affect media coverage (crime rates, more sensational crimes, minority history, etc.) a statistical analysis that accounted for such controls would perhaps yield more satisfying results. In this same vein further research should account for the variables such as publication readership totals, the population of states used in the research, and the relative homogeneity of the populations. A content analysis along the lines such as the one conducted for this thesis perhaps only begins to address questions regarding the expressive effects of bias crime legislation. However, the path taken appears as though it could reveal much valuable information if traveled further. 


\section{Journal Article and Book References}

Altman, A. (2001). The democratic legitimacy of bias crime law: public reason and the political process. Law and Philosophy 20, 2.

Bleich, E. (2007). Hate crime policy in Western Europe: responding to racist violence in Britain, Germany, and France. American Behavioral Scientist 51, 2.

Dixon, L. \& Ray, L. (2007). Current issues and developments in race hate crime. Probation Journal 54, 2.

Epstein, L. \& Walker, T. G. (2009). Constitutional Law for a Changing America: Rights, Liberties and Justice. CQ Press: Washington, D. C.

Hurd, H. M. (2001). Why liberals should hate "hate crime legislation." Law and Philosophy 20, 2.

Iganski, P. (1999). Why make 'hate' a crime? Critical Social Policy 19, 3.

Iganski, P. (2001). Hate crimes hurt more. American Behavioral Scientist 45, 4.

Iganski, P. \& Lagou, S. (2009). How hate crimes hurt more: evidence from the British crime survey. Hate Crimes Vol. 2: The Consequences of Hate Crimes. Eds. Perry, B. \& Iganski, P. Praeger Publishers: Westport, CT.

Jacobs, J. B. \& Potter, K. (1998). Hate Crimes: Criminal Law and Identity Politics. New York:Oxford University Press.

Jenness, V. \& Grattet, R. (1996). The criminalization of hate: a comparison of structural and polity influences on the passage of "bias-crime" legislation in the United States. Sociological Perspectives 39, 1.

Kahan, D. M. (2001). Two liberal fallacies in the hate crime debate. Law and Philosophy 20,2 .

King, R. D., Messner, S. F., \& Baller, R. D. (2009). Contemporary hate crimes, law enforcement, and the legacy of racial violence. American Sociological Review 74.

Leeper, R. (2000). Keegstra and R. A. V.: a comparative of the Canadian and U.S. approaches to hate speech legislation. Communication Law and Policy 5, 3.

Levin, J. \& McDevitt, J. (2002). Hate Crimes Revisited: America's War on Those Who Are Different. Westview Press: Boulder, Colorado. 
Liberman, Michael "Hate Crime Laws: Punishment to Fit the Crime." Dissent Magazine July, 82010.

Lim, H. A. (2009). Beyond the Immediate Victim: Understanding Hate Crimes as Message Crime. Hate Crimes Vol. 2: The Consequences of Hate Crime. Eds. Perry, B. \& Iganski, P. Praeger Publishers: Westport, CT.

Nearpass, G. R. (2003). The overlooked constitutional objection and practical concerns to penalty enhancement provisions of hate crime legislation. Albany Law Review 66.

Phillips, N. D. (2009). The prosecution of hate crimes: the limitations of the hate crime typology.Journal of Interpersonal Violence 24, 5.

Saucier, D. A., Hockett, J. M., Zanotti, D. C., \& Heffel, S. (2010). Effects of racism on perceptions and punishment of intra- and interracial crimes. Journal of Interpersonal Violence 25, 10.

Soule, S. A. \& Earl, J. (2001). The enactment of state-level hate crime law in the United States: intrastate and interstate factors. Sociological Perspectives 44, 3. 